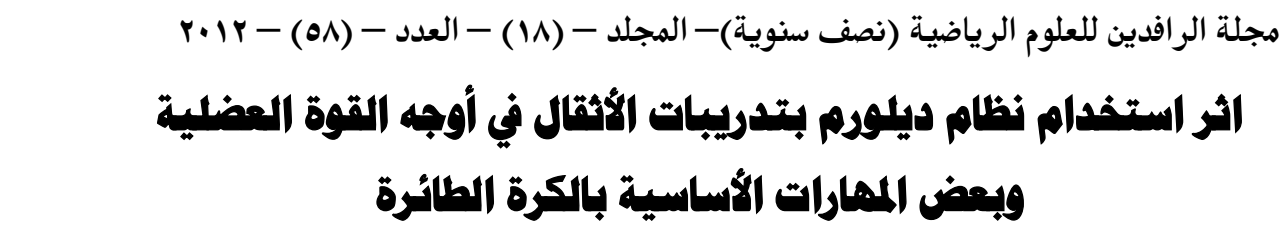

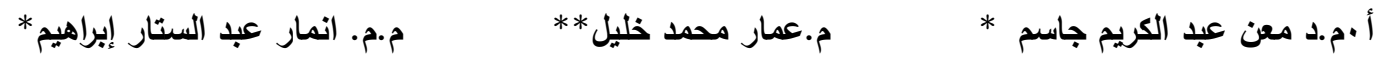

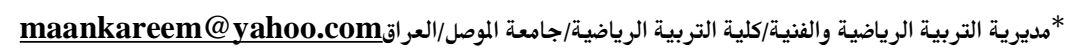

**فرع الألعاب الفردية/كلية التربية الرياضية/جامعة الموصل /العراق.

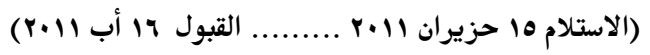

\begin{abstract}
$\underline{\text { unill }}$

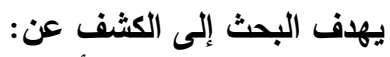

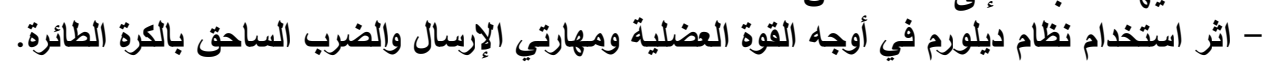

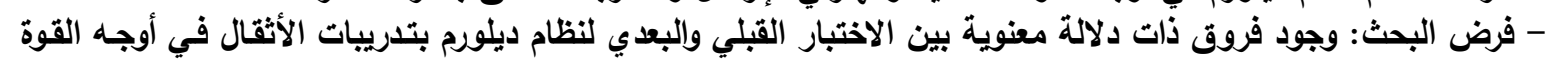

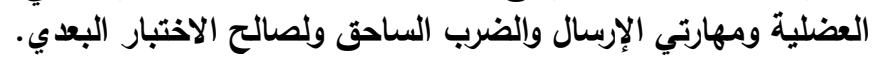

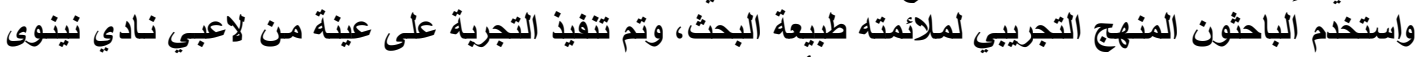

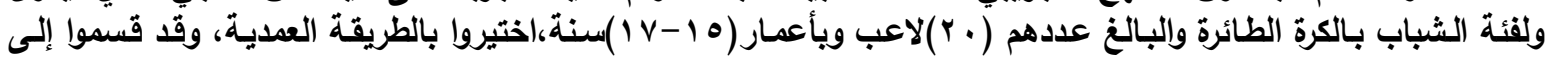

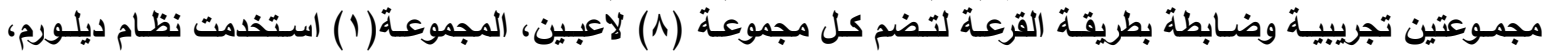

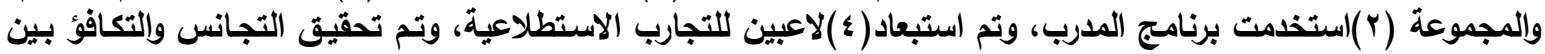

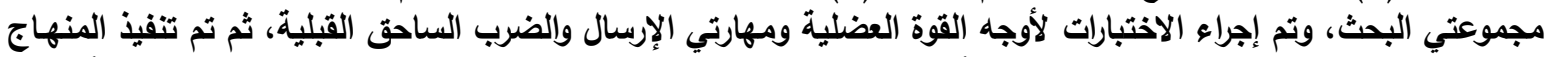

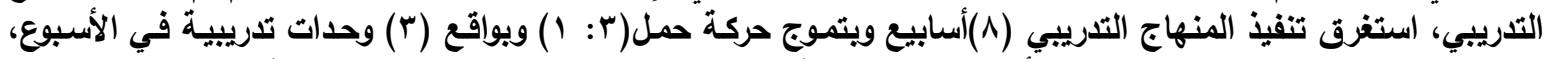

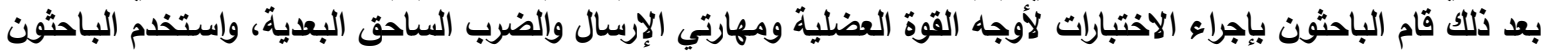

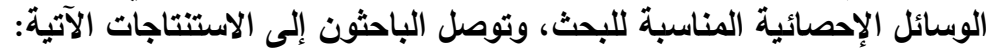

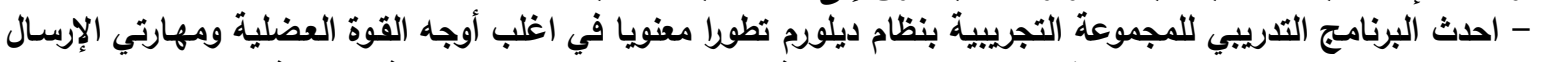

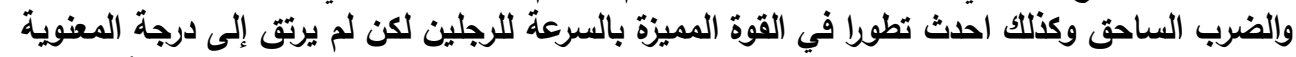

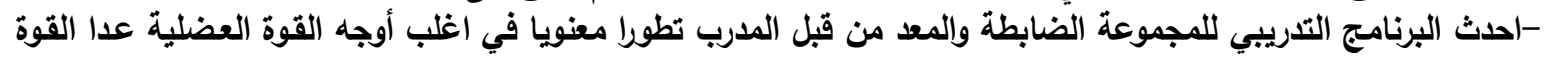

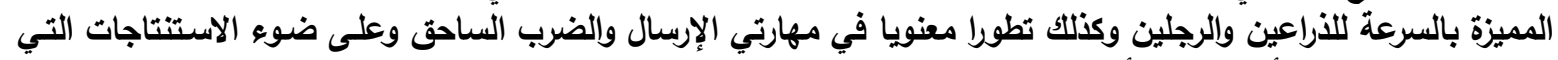

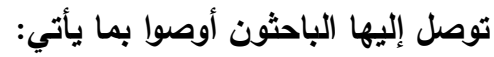

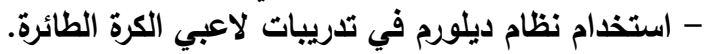

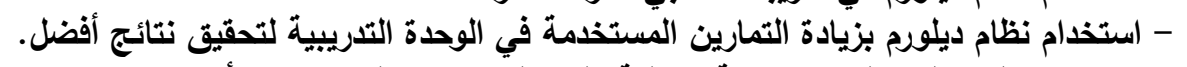

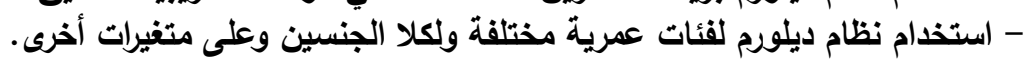

The effect of using the system Delorm weightlifting exercises in aspects

of muscle strength and some basic skills of volleyball

lecturer Dr. Maan A. jasem lecturer Ammar M. Khalil

Asst. Lecturer Anmar A. Ibrahim

\begin{abstract}
There search imstoreveal:

The effect of using the system in Delorm aspects of my skills and muscle power transmission and spike the ball flight. Presumably Search:

There were significant differences between pretest and post system Delorm weightlifting exercises in aspects of my skills and muscle power transmission and spike and the post test. The researchers used the experimental method is adequate to the nature of the research was carried out the experiment on a sample of the players club Nineveh and youth volleyball and who are (20) for the player and ages (15-17 years), were chosen the way intentional, was divided into two experimental and control group in a lottery to include all group (8) players, the group (1) used the system Delorm, and $G$ (2) used the Trainer Program, were excluded (4) players to experience the reconnaissance was to achieve uniformity and parity between the two sets of research, was conducted tests to
\end{abstract}


aspects of muscle strength and my skills transmission and spike tribal, and has been the implementation of the curriculum, it took the implementation of the curriculum (8) weeks and Ptmuj movement Download (3: 1) the rate of (3) training modules in the week, after that, the researchers carried out tests for aspects of muscle strength and my skills transmission and spike dimensional, and the researchers used statistical methods appropriate for research, researchers found the following conclusions:

- Create training program for the experimental group system Delorm advanced significantly in most aspects of my skills and muscle power transmission and spike and create developed in the force characterized by the speed of the arms but has not lived up to the point of moral.

- Create training program for the control group, which was prepared by the instructor developed significantly in most aspects of muscle strength except force characterized by the speed of the arms and legs as well as my skills developed significantly in the transmitter and spike, in the light of the conclusions reached by the researchers have recommended including thefollowing:

-Use system Delorm in training for volleyball players.

- Use system Delorm up exercises used in the module to achieve better results. - Use system Delorm for different age groups and both sexes and on the other variables.

$$
\text { 1 ا التعريف بالبحث: } 1 \text { المقدمة وأهمية البحث: }
$$

إن مجال علم التدريب الرياضي تأثر بالسنوات الأخيرة بثورة العلم والتقنية، إذ اتخذت العملية التذريبية أثكالا واساليباً جديدة وحديثة جعلت طبيعة التدريب نتناسب مع النشاط التخصصي وذلك بهدف الارتقاء بالمستوى البدني والمهاري

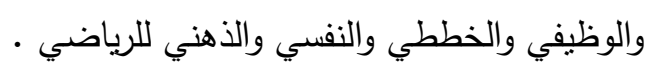
تعد تدريبات الأثقال إحدى الأسـاليب المتبعة في تدريب الكثير من الألعـاب الرياضية، وإن تدريب القوة

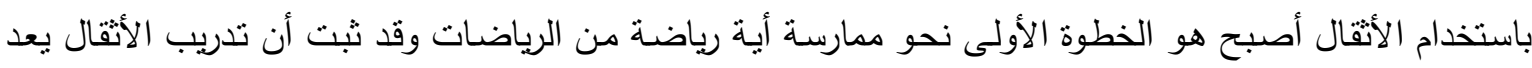
أحد أهم العوامل التي تسهم في تحسين مستوى الأداء وتطوير القدرات البدنية كما انه لا يقتصر على تتمية القوة

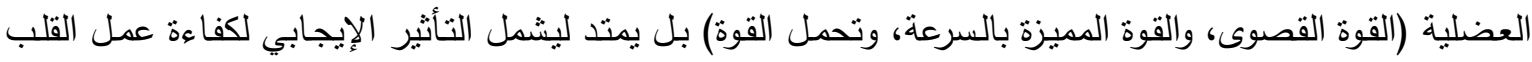


والتي تتمثل بتدريبات القوة وذلك من خلال تحديد عدد التكرارات والمجموعات وأوقات الراحة وأسلوب التنفيذ التي تختلف باختلاف النظام التدريبي. (المندلاوي والثاطئ، 91 (، 0). ونظام ديلورم هو احد الأنظمة التذريبية لتدريبات

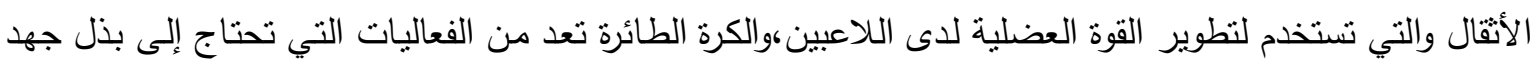
عالي أثناء القيام بأداء المهارات الأساسية الهجومية والدفاعية مثل (الإرسال الساحق، الضرب الساحق، حائط الصد) وهذه المهارات تحتاج إلى عنصر القوة، والذي أصبح الفيصل الوحيد بين الفرق العالمية للحصول على النقاط عند التهاء تقارب مستويات هذه الفرق بباقي الصفات البدنية والمهارية. كما وأن الجميع يستخدمون أساليب ونظم تدريبية مختلفة في تنفيذ تدريبات الأثقال ونظام ديلورم هو أسلوب جديد ينفذ بـه تدريبات الأثقال بنسب مختلفة تتظيمياً عن بقية الأسـاليب في الأداء والنسب والتكرارات. ومن هنا تكمن أهمية البحث في إجراء دراسـة لمعرفة تأثثر استخدام نظام

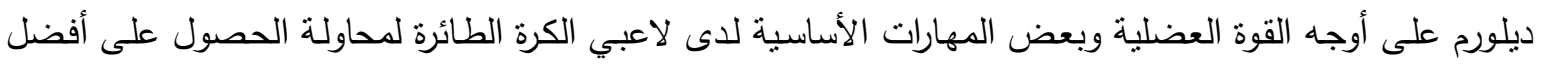

$$
\text { نتائج وأعلى انجاز • }
$$

إن عدم التنوع بطرائق التدريب أي التدريب على وتيرة واحدة كثيـرا مـا يؤدي إلى ثبـات أو أحيانـا هبوط



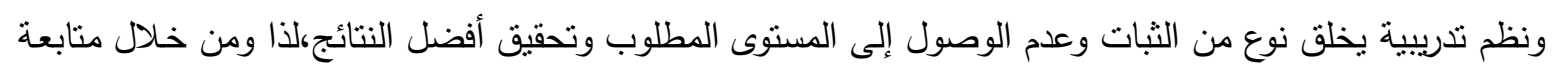




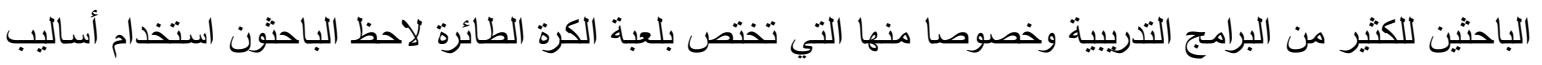

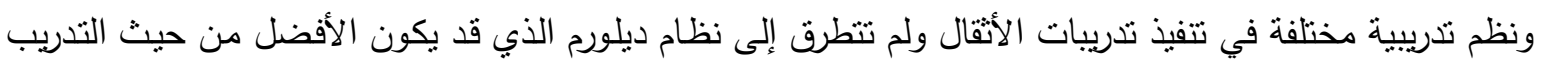

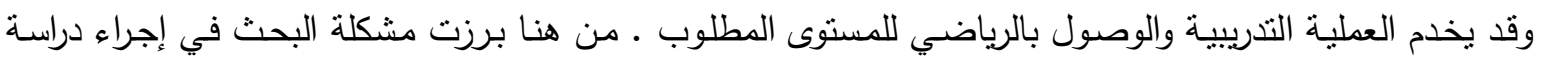
باستخدام الأتقال بنظام ديلورم على أوجه القوة العضلية وبعض الكضاف المهارات الأساسية بالكرة الطائرة.

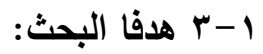

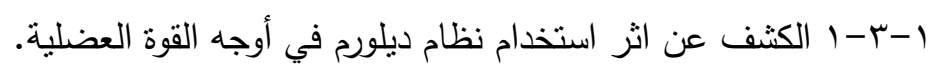
r-r-r-r الكثف عن اثر استخدام نظام ديلورم على بعض المض المهارات الأساسية بالكرة الطائرة.

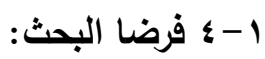
1- ا- - اوجود فروق ذات دلالة معنوية بين الاختبار القبلي والبعدي لنظام ديلورم بتدريبات الأثقال في أوجه القوة العضلية ولصالح الاختبار البعدي.

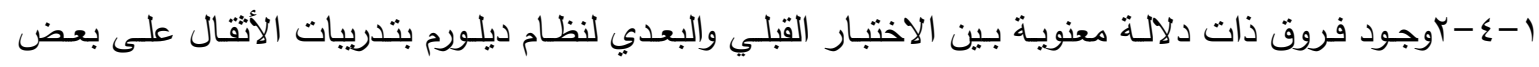
المهارات الأساسية بالكرة الطائرة ولصالح الاختبار البعدي.

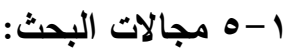

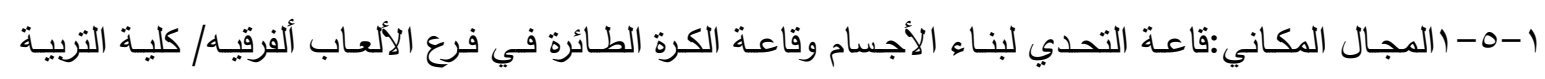
الرياضية- جامعة الموصل

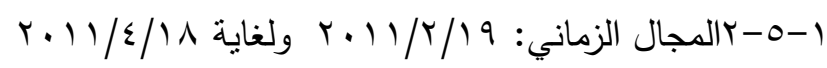

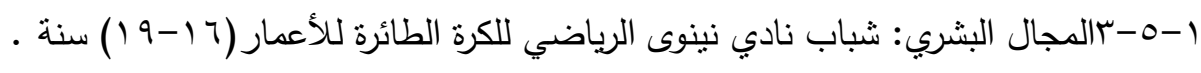

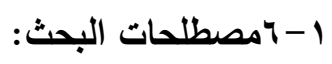

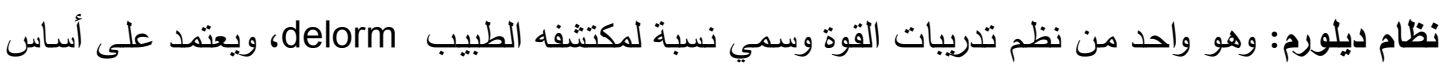

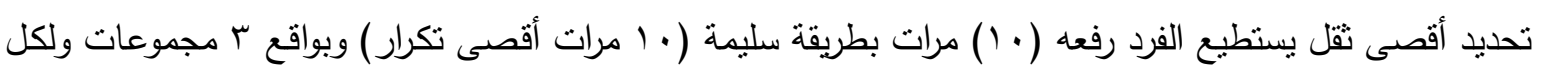

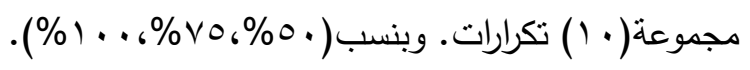

$$
\begin{aligned}
& \text { r - الإطار النظري واللاراسات المشابهة: } \\
& \text { r- بالاطار النظري: }
\end{aligned}
$$

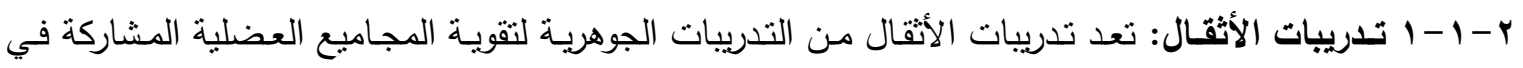

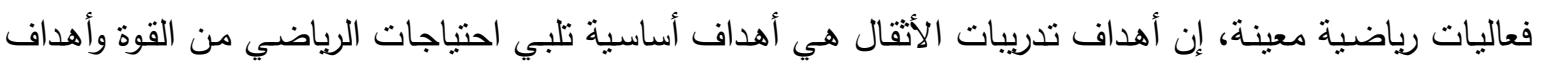

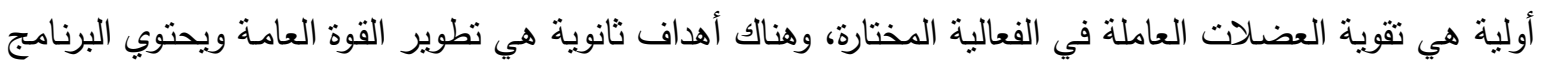

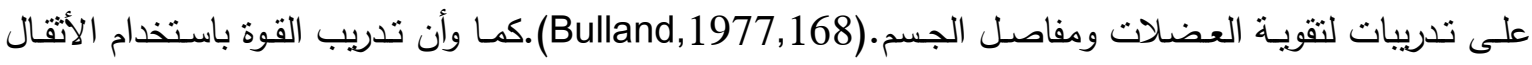

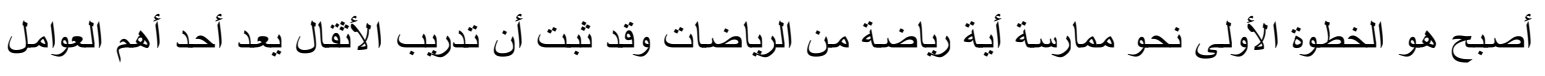

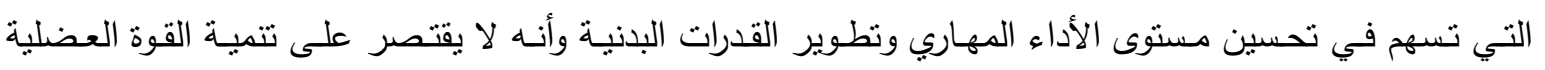

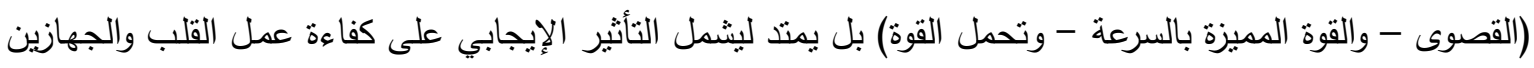

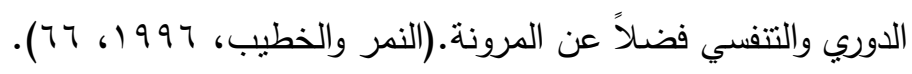

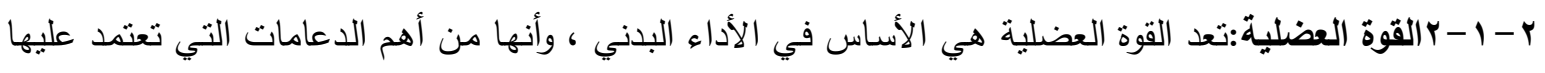

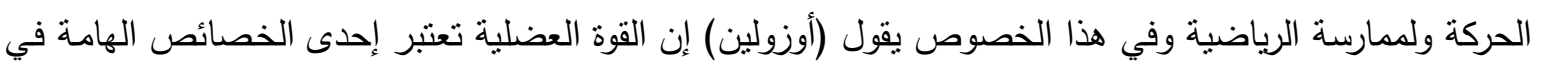

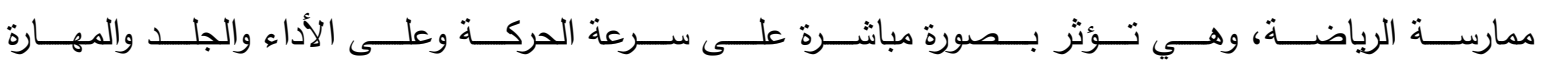
المطلوبة(حسانين، (Y) I , IANV) ، كما و " تعد القوة العضلية أهم مكونات الصفات البدنية حيث يتوقف عليها أداء 


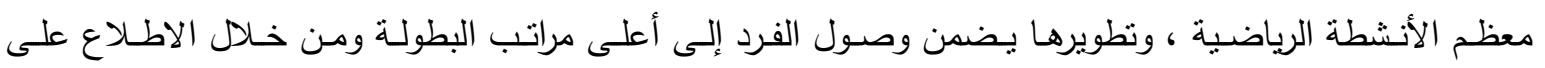

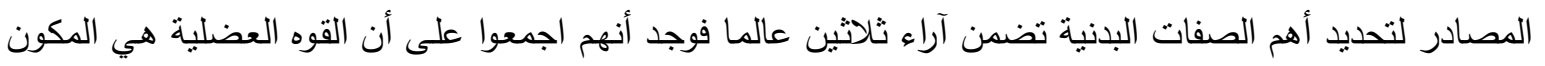

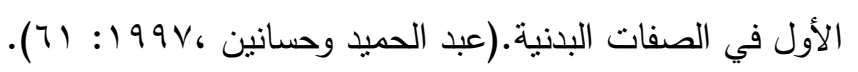

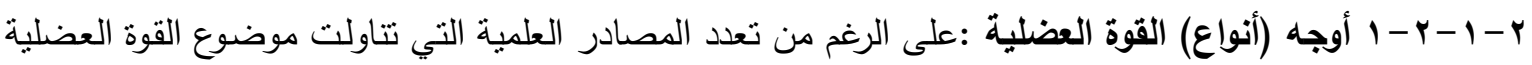

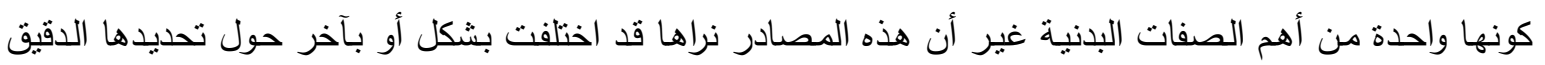

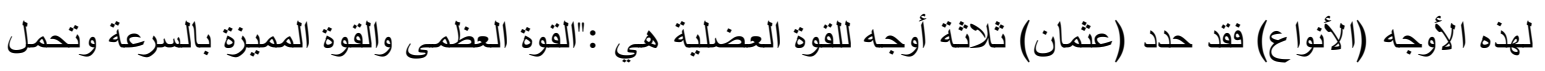

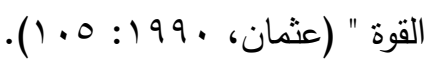
1- القوة الانفجارية:تعد القوة الانفجارية من العناصر الضرورية لأكثر الألعاب الرياضية التي تتطلب القوة والسرعة

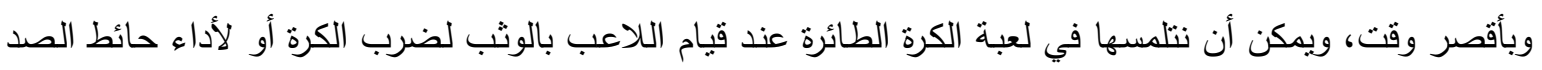

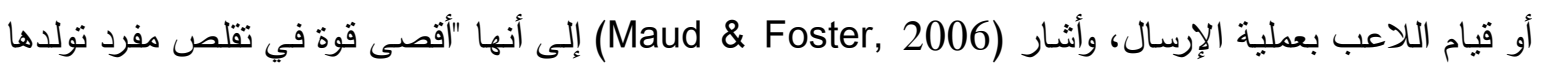
عضلة أو مجموعة عضلية بمعدل سرعة عالي" (Maud \& Foster, 2006, 119)

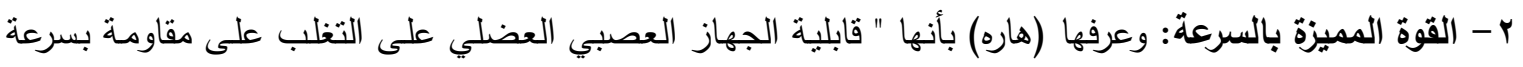

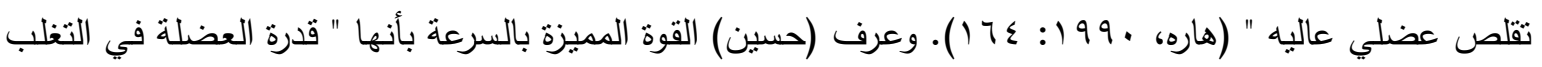

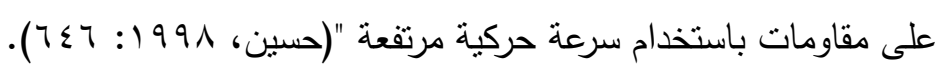

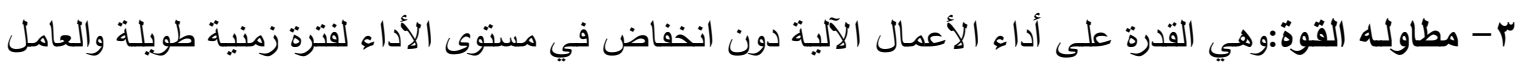

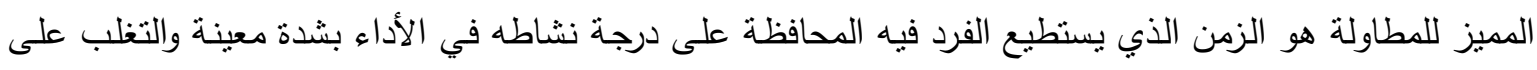

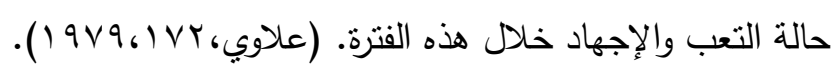
r-1 ب المهارات الأساسية للكرة الطائرة: - الإرسال من الأعلى المواجه (التنسي): يعد أكثر أنواع الإرسال انتشاراً واستعمالاً في المباريات وبين اللاعبين المتقدمين ويعد إرسالاً هادفاً ومحققاً

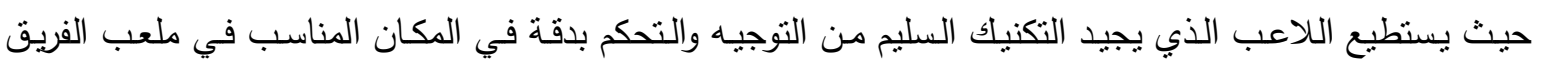

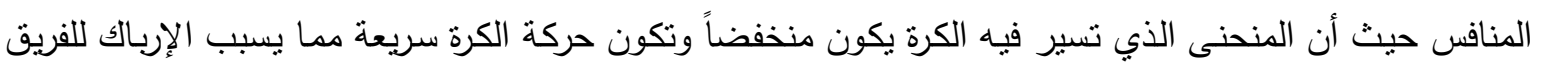

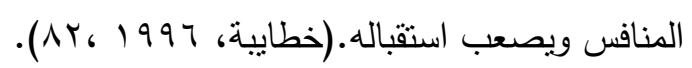

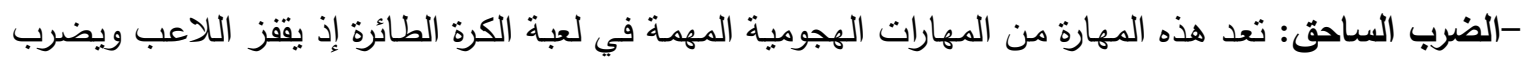

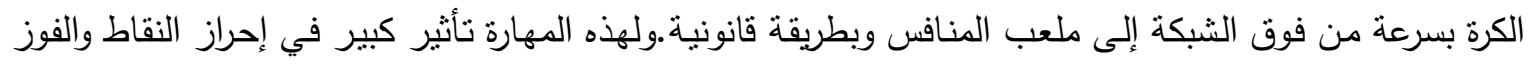

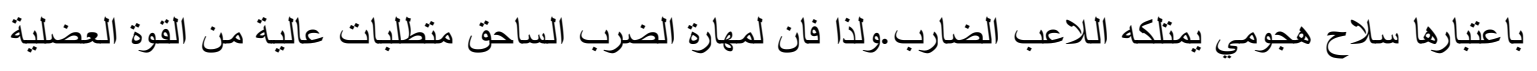

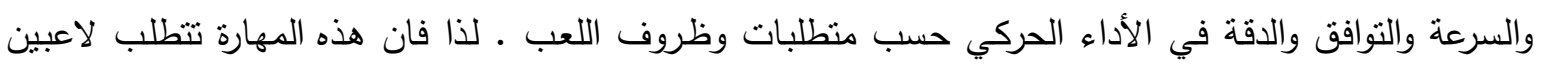

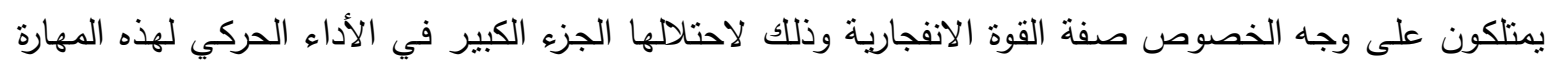

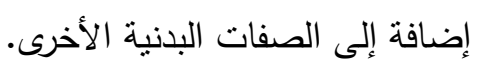

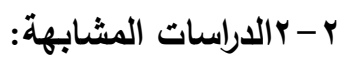



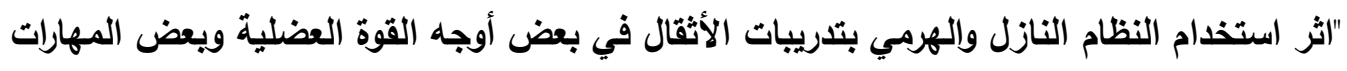

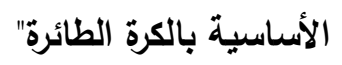

هدف البحث إلى الكثف عن اثر استخدام النظام النازل والنظام الهرمي بتدريبات الأثقال في بعض الكضاك أوجه القوة العضلية وبعض المهارات الأساسية للاعبي الكرة الطائرة. 
استخدم الباحثان المنهج التجريبي، تكونت عينة البحث من لاعبي منتخب شباب محافظة نينوى بكرة الطائرة والبالغ عددهم (1 ( )لاعب وبأعمار (7 (19 (1))سنة،اختيروا بالطريقة العمدية، وقد قسموا إلس مجموعتين تجريبيتين بطريقة القرعة المجموعة(1) استخدمت النظام النازل، والمجموعة (Y)(ستخدمت النظام الهرمي ، استغرق المنهاج

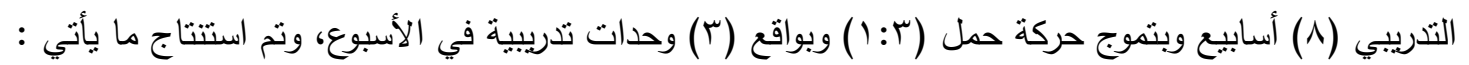

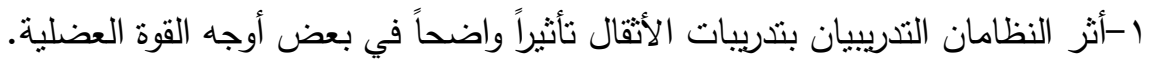

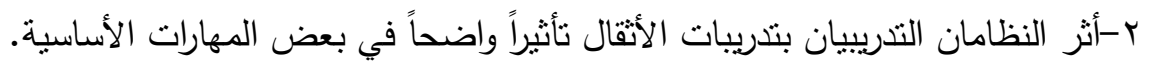

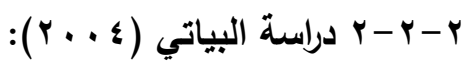

"اثر تدريبات القوة باستخدام الانقباض العضلي الثابت والمتحرك والمختلط في بعض أوجه القوة العضلية والمتغيرات الوظيفية لدى لاعبي كرة اليد الناشئين"

هدف البحث الكشف عن اثر تدريبات القوة باستخدام الانقباض العضلي الثابت في بعض أوجـه القوة

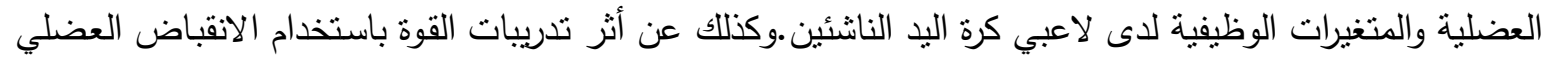

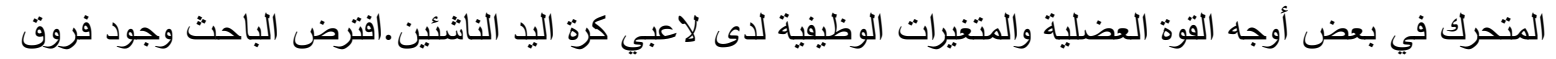
ذات دلالة معنويسة بين الاختبارين القبلي والبعدي في بعض أوجه القوة القوة العضلية والمتغيرات الوظيفية بعد استخدام

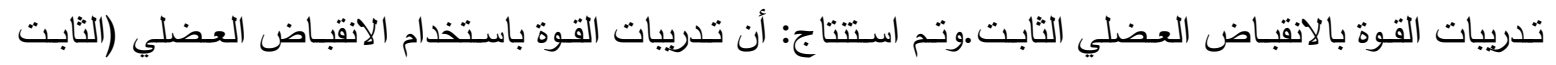

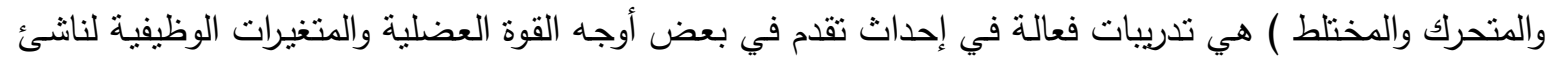
كرة اليد ولكن بنسب مختلفة.

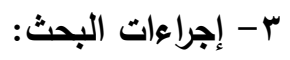
r-1 منهج البحث : استخدم الباحثون المنهج التجريبي لملائمة وطبيعة البحث.

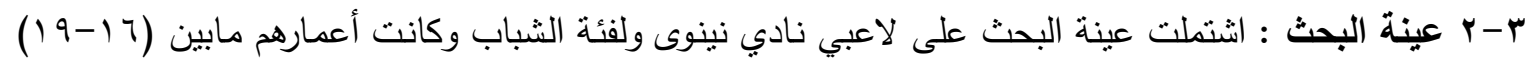

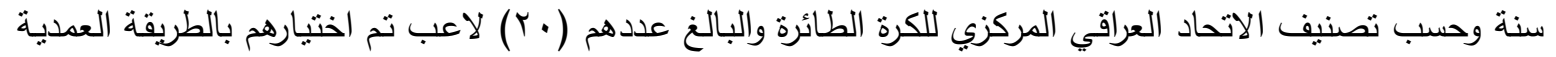
أجريت التجربة الاستطلاعية على (ع) لاعبين ومن ثم نم استبعادهم ليبقى عددهم (7 ( )لاعب قسموا إلى مجموعتين

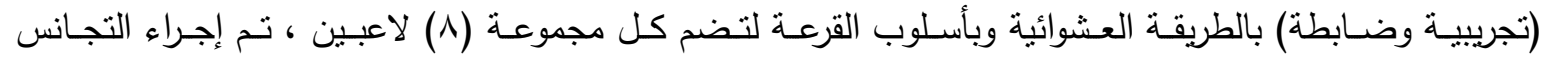

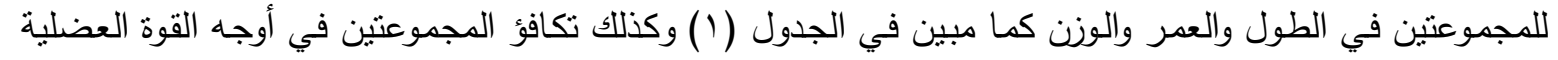

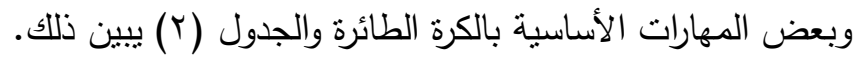
r-r - ا تجـانس مجمـوعتي البحث: تـم إجـراء التجانس على عينـة البحث في متغيـرات العمـر والطول والوزن والجدول (1) بيين ذللك.

الجدول رقم (1) يبين تجانس المجموعتين في متغيرات الطول والعمر والوزن

\begin{tabular}{|c|c|c|c|c|c|c|}
\hline \multirow{2}{*}{ قيمة (ت) } & \multirow{2}{*}{ قيمة ت المحسوبة } & \multicolumn{2}{|c|}{ الضابطة } & \multicolumn{2}{|c|}{ التجريبية } & \\
\hline & & $\varepsilon^{ \pm}$ & س - & $\varepsilon^{ \pm}$ & س - & \\
\hline \multirow{3}{*}{$r, 1 \varepsilon$} & 1,89 & $v, q$ & $|V|, \mid$ & $\varepsilon, 0$ & 179,8 & الطول \\
\hline & $\cdot, r V$ & $1,7 \varepsilon$ & IN,IY & $\cdot, 91$ & IA, rV & العمر \\
\hline & $\cdot, \mathrm{Vq}$ & $\varepsilon, 91$ & $V \varepsilon, r V$ & $\mu, \mu \wedge$ & vq & الوزن \\
\hline
\end{tabular}

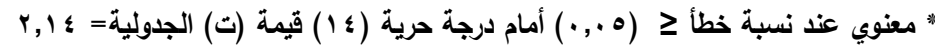




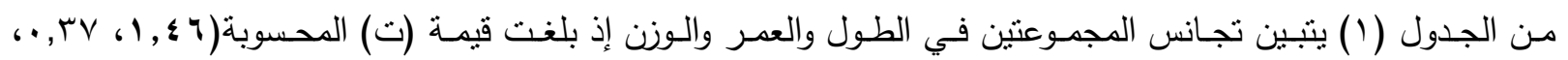

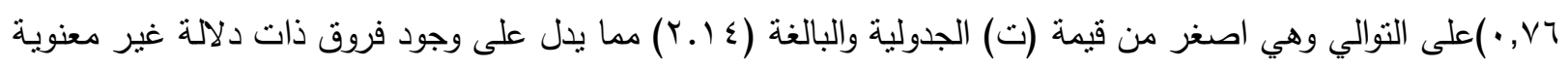



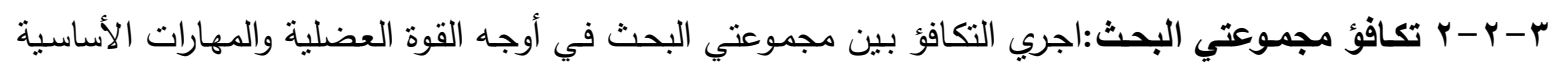



الجدول رقم(r) يبين الأوساط الحسابية والانحرافات المعيارية وقيمة (ت) المحسوية في أوجه القوة العضلية والمهارات الأساسية بين مجموعتي البحث

\begin{tabular}{|c|c|c|c|c|c|c|c|}
\hline \multirow{2}{*}{ الجدولية } & \multirow{2}{*}{ المحسوية } & \multicolumn{2}{|c|}{ المجموعة الضابطة } & \multicolumn{2}{|c|}{ المجموعة التجريبية } & \multirow{2}{*}{ والقياس } & \multirow{2}{*}{ المهارات } \\
\hline & & $\varepsilon \pm$ & س- & $\varepsilon \pm$ & س- ( - س- & & \\
\hline \multirow{8}{*}{ r. $1 \varepsilon$} &. .4 & 1.r. & EV.IT & $1 . . r \mu$ & 0. ro & 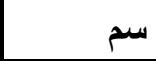 & القوة الانفجارية للرجلين \\
\hline & $1 . r \wedge$ &. .19 & 0.£. &. .11 & 0.90 & متر & القوة الانفجارية للاراعين \\
\hline & $1 . \varepsilon \Lambda$ & 1.19 & ro & r.Av & TV.IT & تكرار & مطاولة القوة للرجلين \\
\hline & $.0 \%$ & $r . \uparrow$ & IV.IY & 1.41 & $17 . \mathrm{TV}$ & تكرار & مطاولة القوة للأراعين \\
\hline &. .99 & .rY & $0.9 \mathrm{r}$ & $. r \leqslant$ & 8.11 & 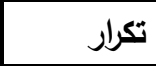 & القوة المميزة بالسرعة للرجلين \\
\hline &. .71 &..$\leqslant 4$ & 9.10 &. .94 & 9 & تكرار & القوة المميزة بالسرعة للأراعين \\
\hline & .0 &. .91 & TH.TY & $1 . .7$ & rT.rV & درجة & الإرسال \\
\hline &.$r \varepsilon$ &.$\wedge r$ & $1 T .1 \%$ & 1.17 & Ir.ro & 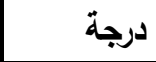 & الضرب الساحق \\
\hline
\end{tabular}

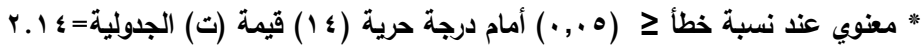

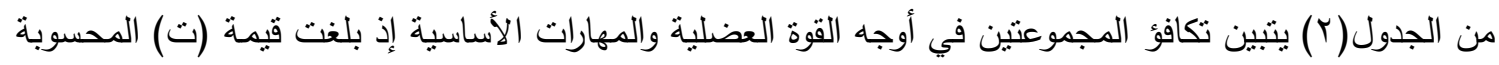

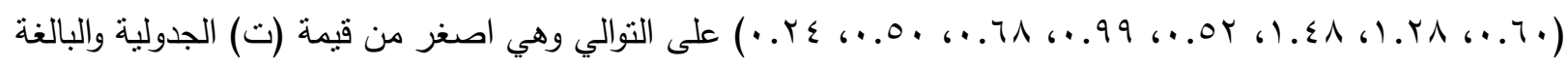

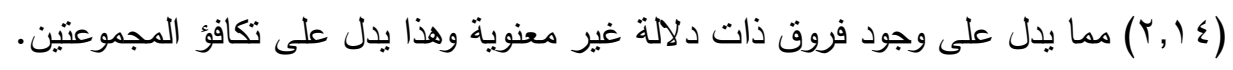

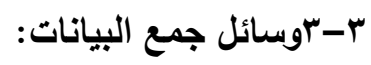
نم استخدام الاستيبان والاختبارات والمقاييس لجمع البيانات.

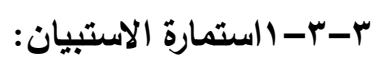

r-r-1-1 استمارة استبيان لغرض تحديد أوجه القوة العضلية الخاصة بلاعبي الكرة الطائرة:

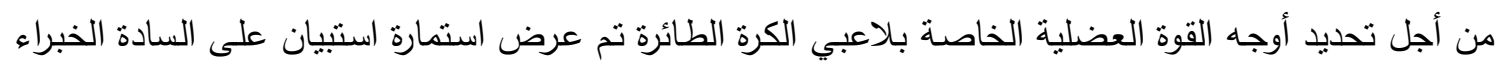

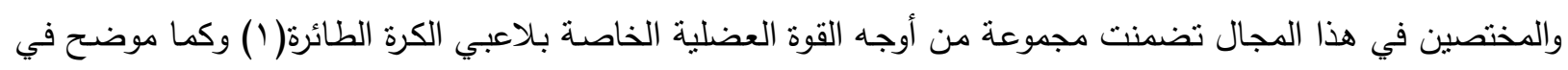

كلية التربية الرياضية /جامعة الموصل

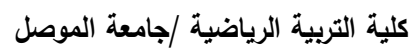
كلية التربية الرياضية /جامعة الموصل

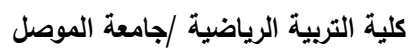
كلية التربية الرياضية /جامعة الموصل الرياضية /امعة العصل كلية التربية الرياضية /جامعة الموصل الرياضية /جاملة العلية كلية التربية الرياضية /جامعة الموصل الرياضل

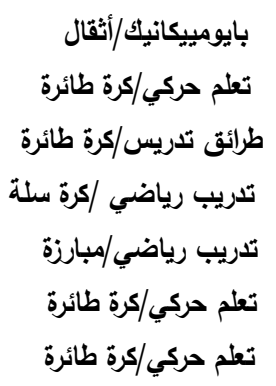

بايومييكانيك/أثقال تطم حركي/كرة طائرة طرائق تلريس/كرة طائرة تدريب رياضي /كرة سلة تدريب رياضي/مباززة تعلم حركي/كرة طائرة

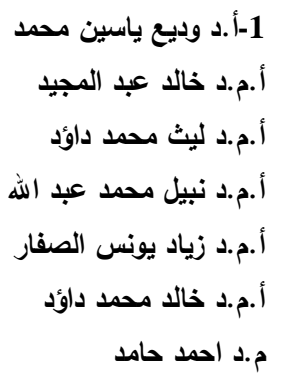


ملحق رقم ( ) (وتم تحديد أوجه القوة العضلية من قبل السادة الخبراء والمختصين والتي حصلت على نسبة اتفاق (اتفاق

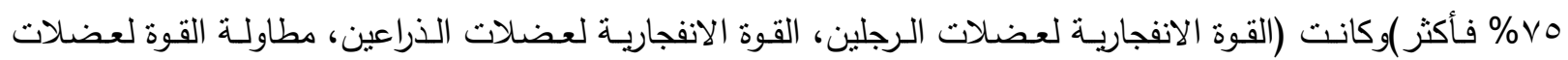
الرجلين، مطاولـة القوة لعضلات الذراعين، القوة المميزة بالسرعة لعضلات الذراعين، القوة المميزة بالسرعة لعضلات

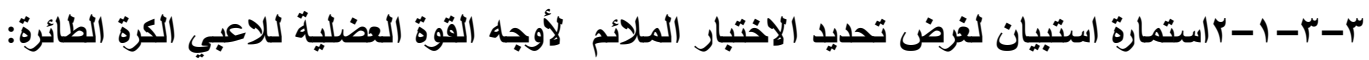
من اجل تحديد الاختبار الملائم لكل وجه من أوجه القوة العضلية تم عرض استمارة استبيان على السادة الخبراء

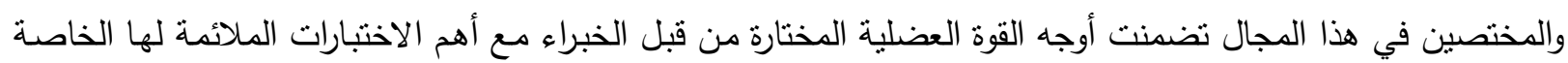
بلاعبي الكرة الطائرة(r) وكما موضتح في ملحق رقم (Y).

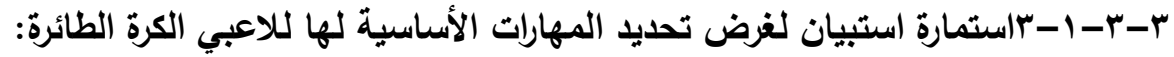

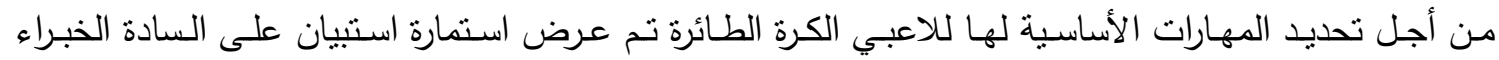
والمختصين في هذا المجال تضمنت مجموعة من المهارات الأساسية للاعبي الكرة الطائرة(r) وكما موضح في ملحق رقم

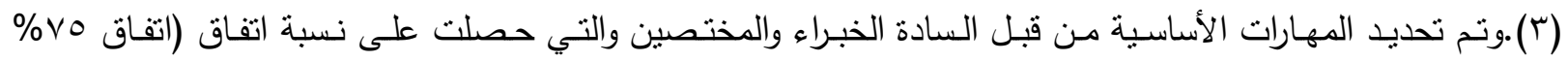
فأكثر)،(ونم اختبار بعض المهارات المحددة من قبل الخبراء وهي (الإرسال، الضرب الساحق). r-r-1-rاستمارة استبيان لغرض تحديد الاختبارات المناسبة للمهارات المحددة للاعبي الكرة الطائرة:

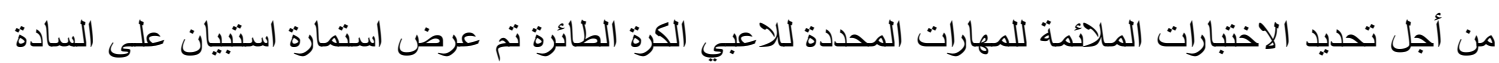
الخبراء والمختصين في هذا المجال تضمنت مجموعة من الاختبارات لكل مهارة(ع) وكما موضح في ملحق رقم (ع). وتم

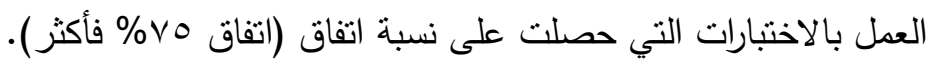
r-

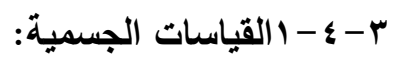

قياس الطول: استخدم الباحثون شريط قياس لقياس الطول. قياس كتلة الجسم: استخدم الباحثون ميزان الكتروني في قياس الكتلة لأفرب مئة غم.

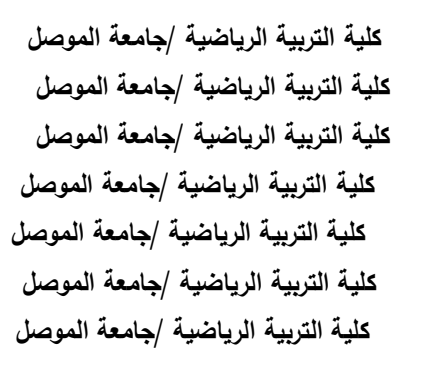

كلية التربية الرياضية /جامعة الموصل

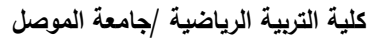

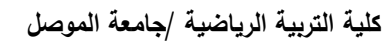

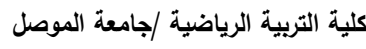

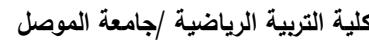

\author{
بايومييكانيك/أثقال \\ تعلم حركي/كرة طائرة \\ طرائق تدريس/كرة طائرة \\ اختبارات/العاب مضرب \\ قياس وتقويم/العاب مضرب \\ تعلم حركي/كرة طائرة \\ تعلم حركي/كرة طائرة
}

$\varepsilon, 4$

أ.د وديع ياسين محمد خليل

أ.م.د خالد عبد المجيد

أ.م. أ. ليث محمد داؤد عبد المجيد

أ.م.د إيثار عبد الكريم

أ.م. أد سبهان محمود الزهيري

أ.م.د خالد محمد داؤد

م.د احمد حامد السويدي دمثل داولي 
r- ع - r الاختبارات البذنية لأوجه القوة العضلية:

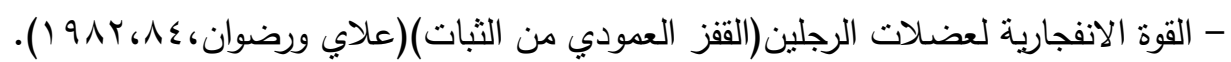

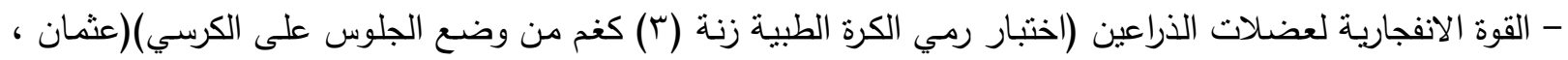
.

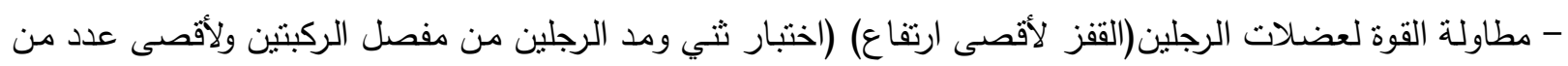

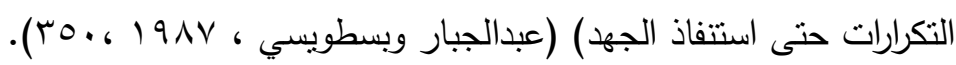
- مطاولة القوة لعضلات الذراعين (اختبار ثني ومد الذراعين من الانبطاح المائل حتى التعب)

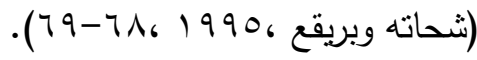

- القوة المميزة بالسرعة لعضلات الذراعين (الاستتاد الأمامي ثني ومد الذراعين لمدة (· ( ) ثانية) - القوة الميزة بالسرعة لعضلات الرجلين (ثلاث حجلات لأكبر مسافة ممكنة ولكل رجل على الألى حدا)

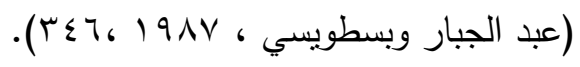

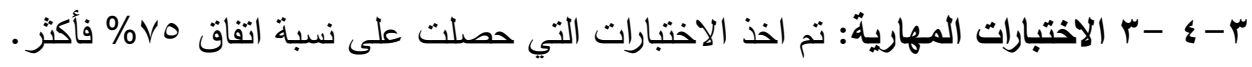
- مهارة الضرب الساحق (اختبار دقة مهارة الضرب النار الساحق).

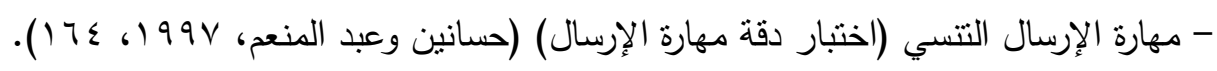

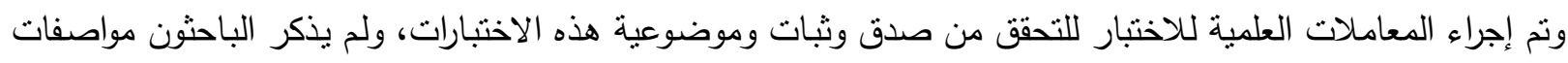

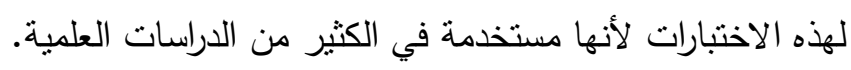

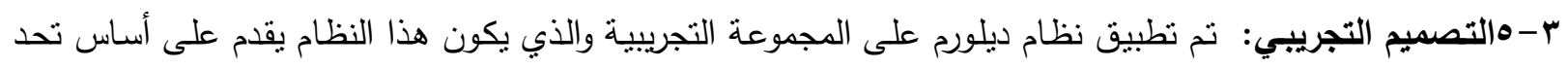

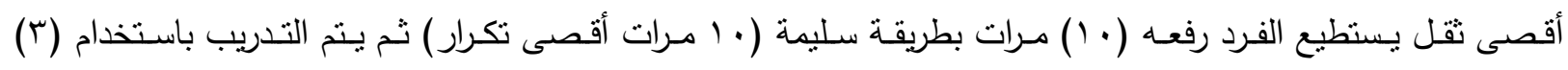

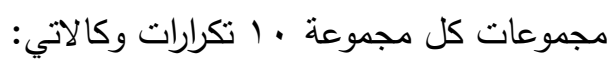

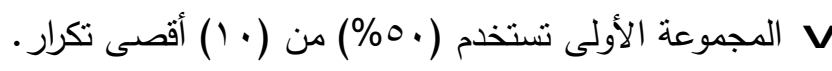

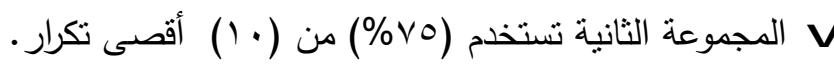

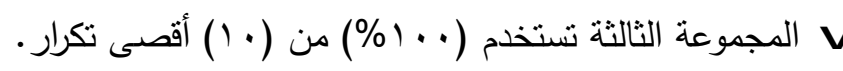
أما المجموعة الثانية تطبق النظام الاعنيادي (التقليدي) بتدريبات الأنقال.

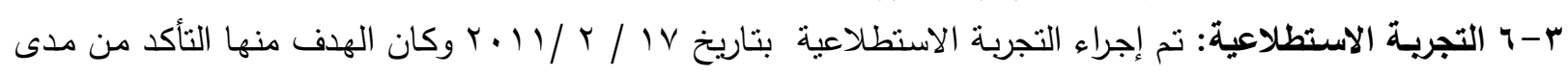

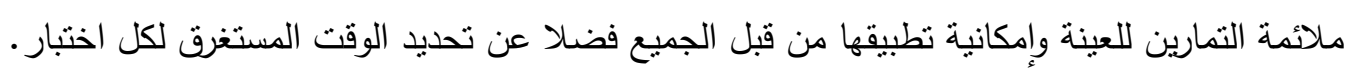
V V-r

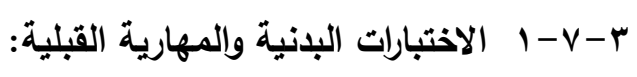

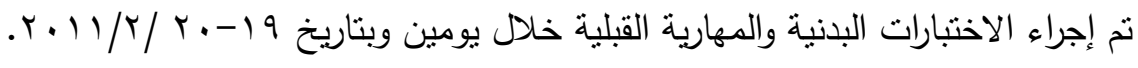

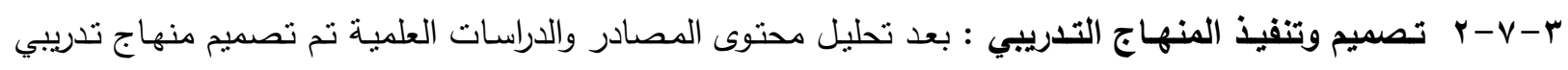

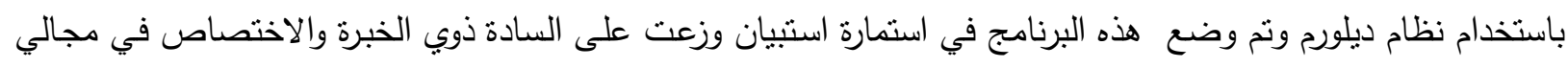

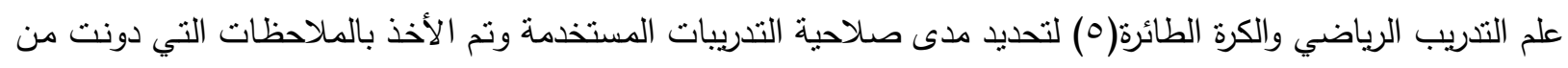

كلية التربية الرياضية /جامعة الموصل كلية التربية الرياضية /جامعة الموصلة الرياضية /امعة الموصل كلية التربية الرياضية /جامعة الموصل الرياضل المعلة الروصل كلية التريية الرياضية /جامعة الموصل الرياضبة الملية

\author{
تلدريب رياضي \\ تعلم حركي/كرة طائرة \\ طرائق تدريس/كرة طائرة \\ تدريب رياضي
}

ه-أ.د أياد محمد عبد الله

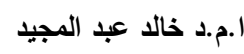
ا. ا.م.د ليث محمد داؤد اليدال

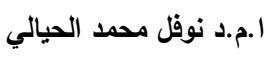




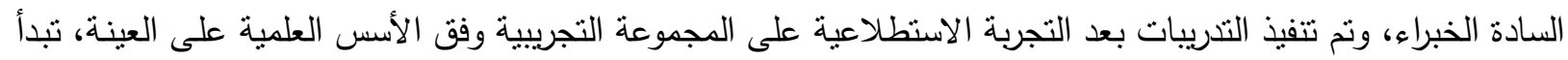

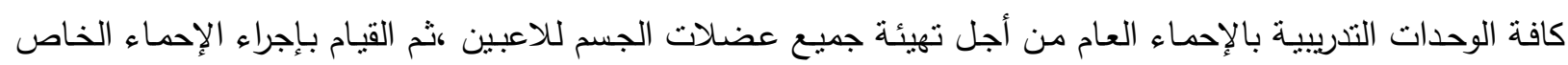

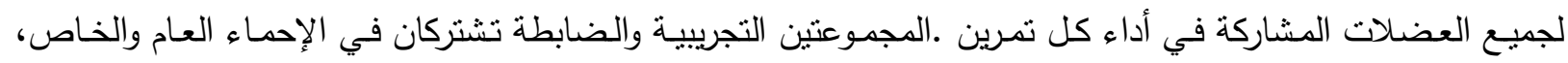

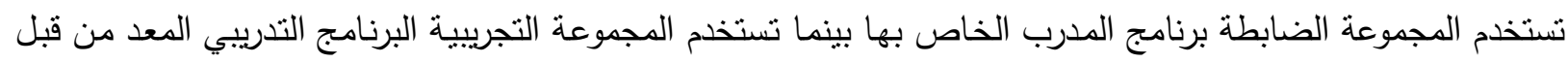

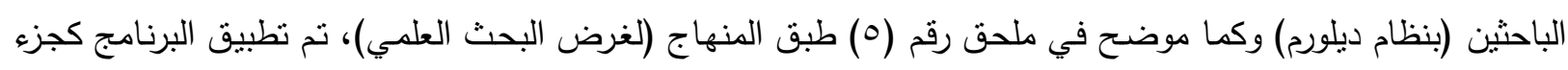

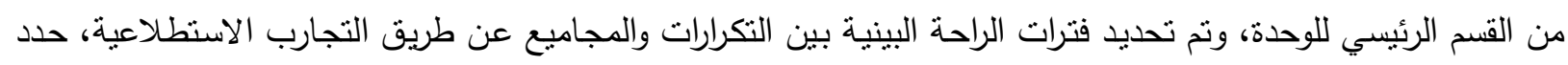

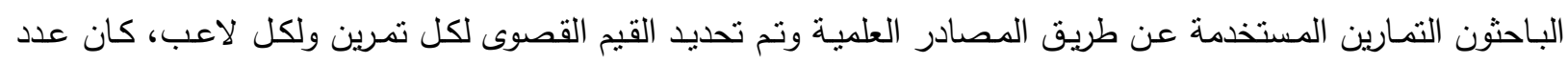

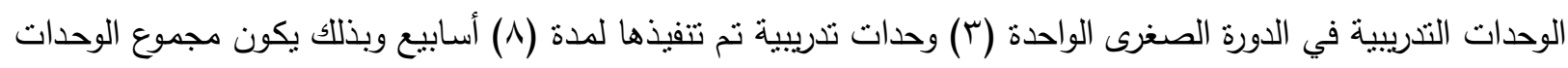

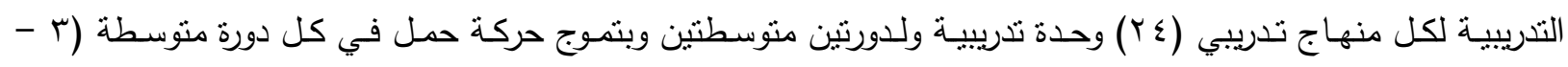

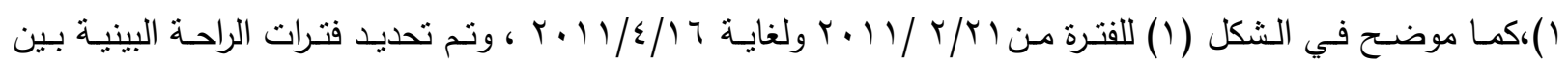

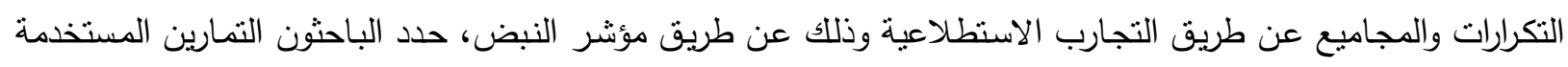

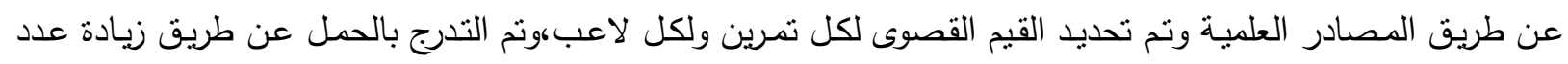

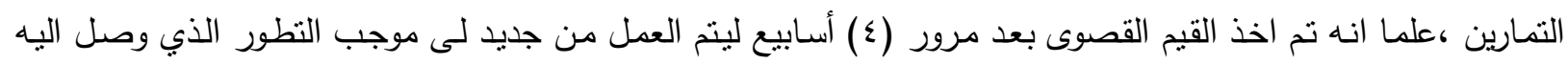

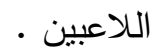

\begin{tabular}{|c|c|c|c|c|c|c|c|c|}
\hline \multicolumn{4}{|c|}{ الدورة المتوسطة الثانية } & \multicolumn{4}{|c|}{ الدورة المنوسطة الاولى } & \multirow{3}{*}{ لألابورة المتوسطة } \\
\hline الاســـبوع & الالســبوع & الاســبـوع & الاســبـوع & الاســـوع & الاســـبوع & الاســبـوع & الاســـبوع & \\
\hline الثامن & السابع & السادس & الخامس & 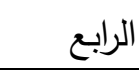 & الثالث & الثاني & الاول & \\
\hline & & & & & 】 & & & حمل أقصىى \\
\hline & & * & - & & & $\varnothing$ & $\longrightarrow$ & حمال عالي \\
\hline 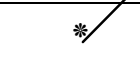 & & & & - * & & & & حمل متوسط \\
\hline
\end{tabular}

شكل (1) يوضح تموج حركة الحمل

r r- r r الاختبارات البانية والمهارية البعدية:

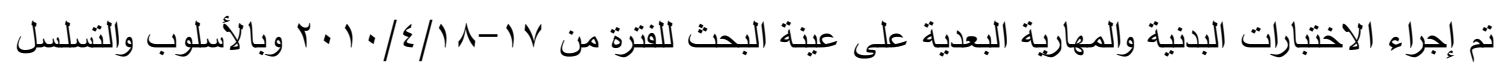

الذي أجريت بهما الاختبارات البننية والمهارية القبلية نفسها.

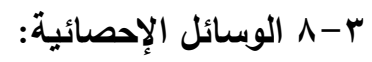

تم استخراج الوسائل الإحصائية من خلال الاعتماد على الحقيبة الإحصائية (SPSS) بوساطة الحاسبة الآلية

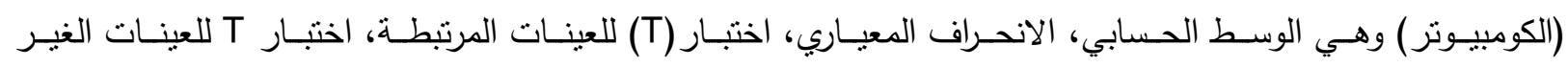

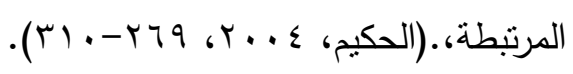

كلية التربية الرياضية /جامعة الموصل

كلية التربية الرياضية /جامعة الموصل لريله /جامعله
التتريب الرياضي

تعلم حركي/كرة طائرة
م.د نبيل محمد عبد الله

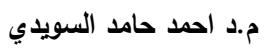


الجدول رقم(ب) يبين الأوساط الحسابية والانحرافات المعيارية وقيمة (ت) المحسوبة لأوجه القوة العضلية

والمهارات الأساسية للاختبارين القبلي والبعدي للمجموعة التجريبية.

\begin{tabular}{|c|c|c|c|c|c|c|c|}
\hline \multirow{2}{*}{ |لجدئ } & \multirow{2}{*}{ قيمسة (ت) } & \multicolumn{2}{|c|}{ الاختبار البعدي } & \multicolumn{2}{|c|}{ الاختبار القبلي } & \multirow{2}{*}{ والقياس } & \multirow{2}{*}{ أوجه القوة العضلية } \\
\hline & & $\varepsilon^{+}$ & س & $\varepsilon^{+}$ & س & & \\
\hline \multirow{8}{*}{ Y.MT } & $* q, r v$ & $1 . .40$ & Or.rV & $1 . . r \mu$ & $0 ., Y_{0}$ & سم & القوة الانفجارية للرجلين \\
\hline & $* \bullet, \S \wedge$ &. .91 & ד.r. &. .11 & 0.90 & متر & القوة الانفجارية للأراعين \\
\hline & $* \vee, 01$ & $\varepsilon$ & r & r.AV & rV.IT & تكرار & مطاولة القوة للرجلين \\
\hline & $\because q . . r$ & $1 . \wedge \mu$ & in.vo & 1.71 & $17 . r \mathrm{~V}$ & تكرار & مطاولة القوة للذراعين \\
\hline & $1, \lambda r$ & 1.4 & 1.00 & .94 & 9 & تكرار & القوة|لمميزة بالسرعة للأراعين \\
\hline & $* 0.71$ & שr & T.r & \& & 9.11 & تكرار & القوة المميزة بالسرعة للرجلين \\
\hline & $* 0 . r \mu$ & 1.17 & YV.TY & $1 . .7$ & rT.rv & درجة & الإرسال \\
\hline & *\%.97 & r.०1 & $17.4 \mathrm{~V}$ & 1.17 & IT.YO & درجة & الضرب الساحق \\
\hline
\end{tabular}

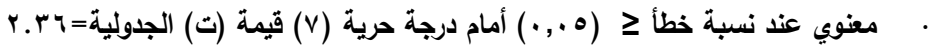

من خلال ملاحظتنا للجدول (ץ) يتبين لنا ما يأني: - وجود فروق ذات دلالة معنوية في جميع أوجه القوة العضلية بين الاختبارين القبلي والبعدي ولصالح الاختبار البعدي

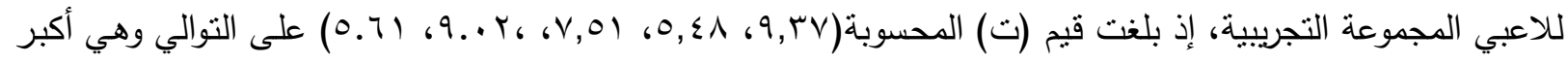

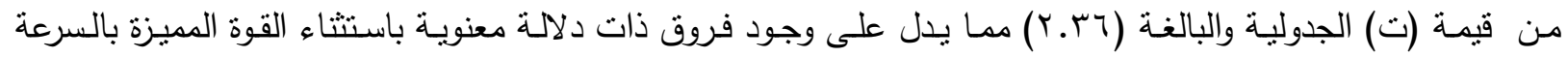

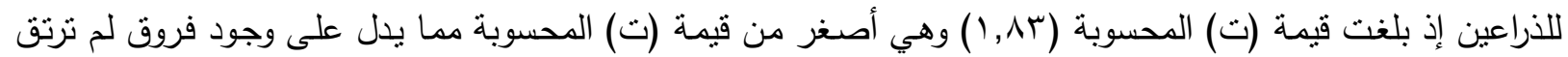
إلى درجة المعنوية.

- وجود فروق ذات دلالة معنوية في مهارتي الإرسال والضرب الساحق بين الاختبارين القبلي والبعدي ولصالح

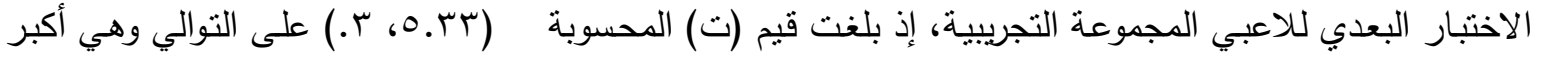

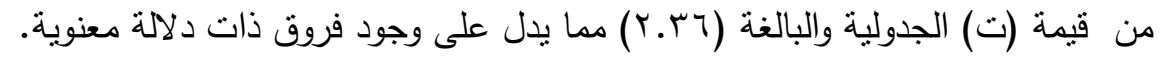


ع - 1-rعرض نتائج الاختبارات القبلية والبعدية للمجموعة الضابطة وتحليلها:

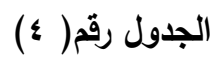

يبين الأوساط الحسابية والانحرافات المعيارية وقيمة (ت) المحسوبة لأوجه القوة العضلية

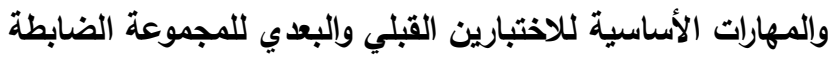

\begin{tabular}{|c|c|c|c|c|c|c|c|}
\hline \multirow{2}{*}{ 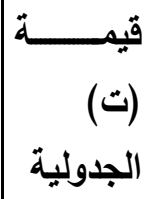 } & \multirow{2}{*}{ قالمحسو (تة } & \multicolumn{2}{|c|}{ الاختبار البعدي } & \multicolumn{2}{|c|}{ الاختبار القبلي } & \multirow{2}{*}{ 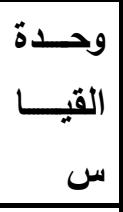 } & \multirow{2}{*}{ أوجه القوة العضلية } \\
\hline & & $\varepsilon^{+}$ & 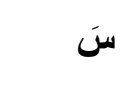 & $\varepsilon^{+}$ & سنَ & & \\
\hline \multirow{8}{*}{ Y.M } & $* 0.71$ & $1 . .9$. & $\varepsilon \Lambda .7 r$ & $1 . . \mu_{0}$ & $\varepsilon V .1 Y$ & 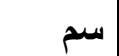 & القوة الانفجارية للرجلين \\
\hline & $*$ Y.0 & $1 \cdots v$ & 0.09 &.$\wedge 9$ & ๑.乏. & 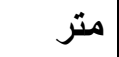 & القوة الانفجارية للأراعين \\
\hline & $* 4.1 \mathrm{~V}$ & 1.09 & Y7. TY & 1.19 & ro & تكرار & مطاولة القوة للرجلين \\
\hline & $* v .9 r$ & $r . \wedge \Lambda$ & IN.TY & ץ.५ & IV.IY & تكرار & مطاولة القوة للاراعين \\
\hline & I.rr & $1 . r \Lambda$ & 9.10 & 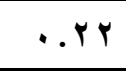 & $0.9 r$ & تكرار & القوة|لمميزة بالسرعة للأراعين \\
\hline &. .99 &.$r^{4}$ & $7 .+1$ & $\cdot . \leqslant 4$ & q.Y० & تكرار & القوة المميزة بالسرعة للرجلين \\
\hline & $* 7 . .7$ & 1.01 & Y५.V० & .991 & rr.Tr & درجة & الإرسال \\
\hline & $* \div .71$ & 1.87 & 10.7r & . . & $1 r .1 r$ & ل درجة & الضرب الساحق \\
\hline
\end{tabular}

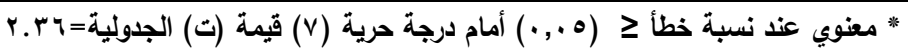

. من خلال ملاحظتنا للجدول ( ع ) يتبين:

-وجود فروق ذات دلالمة معنويـة في جميع أوجه القوة العضلية بين الاختبارين القبلي والبعدي ولصالح الاختبار

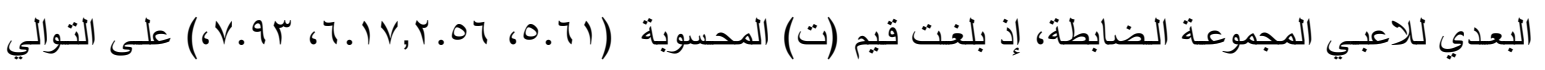

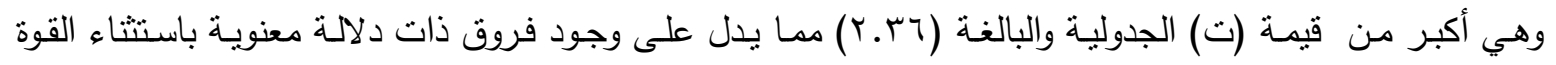

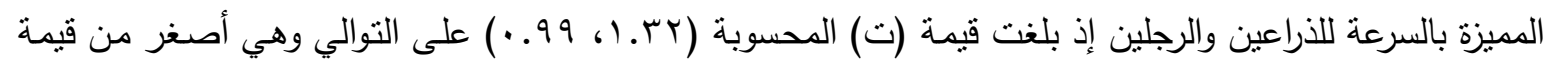

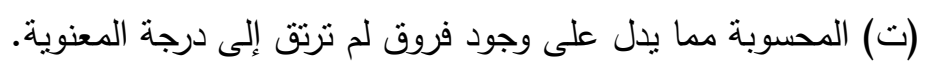

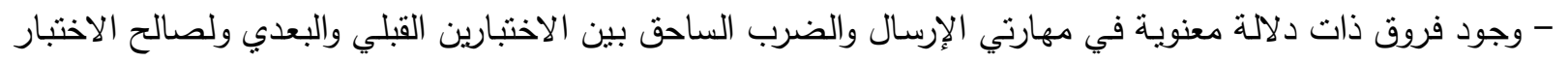

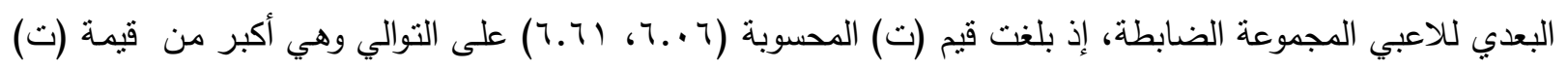

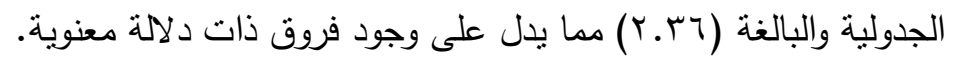




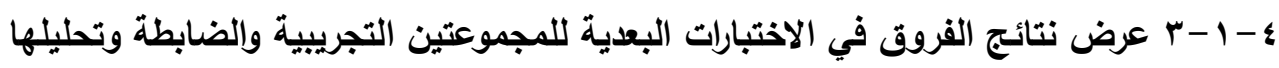

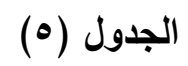

يبين الأوساط الحسابية والانحرافات المعيارية وقيمة (ت) المحسوبة لأوجه القوة العضلية والمهارات الأساسية للاختبارين البعديين للمجموعتين التجريبية والضابطة

\begin{tabular}{|c|c|c|c|c|c|c|c|}
\hline \multirow[t]{2}{*}{ قيمة (ت) } & \multirow{2}{*}{ 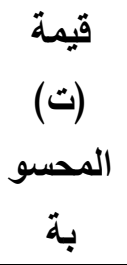 } & \multicolumn{2}{|c|}{ للمجموعة الضابطة البعدي } & \multicolumn{2}{|c|}{ للاجموعة التجريبية البعدي } & \multirow[t]{2}{*}{ وحدة } & \multirow{2}{*}{ أوجه القوة العضلية } \\
\hline & & $\varepsilon+$ & 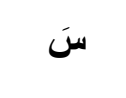 & $\varepsilon+$ & سنَ سن & & \\
\hline \multirow{8}{*}{$r, 1 \leq$} & $\cdot, \mathrm{v} \cdot$ & 1.9. & $\varepsilon \Lambda .7 Y$ & ه & Or,rv & 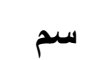 & القوة الانفجارية للرجلين \\
\hline & $1, \mathrm{r}$ & $1 \ldots v$ & 0.09 & $\cdot, 9 \wedge$ & $\checkmark, r$. & 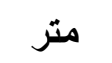 & القوة الانفجارية للاراعين \\
\hline & $* \curlyvee, \wedge \vee$ & 1.09 & r..7r & $\varepsilon$ & r & 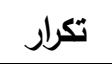 & مطاولة القوة للرجلين \\
\hline & $\cdot, \wedge$ & $r . \wedge \wedge$ & $1 \wedge .7 r$ & $1, \wedge r$ & $1 \wedge, \vee 0$ & 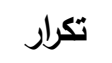 & مطاولة القوة للأراعين \\
\hline & 1 & $1 . \mu \wedge$ & 9.10 & 1,7 & $1 \cdot, 0$ & 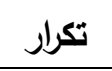 & القوة|لمميزة بالسرعة للذراعين \\
\hline & $1, r$. & . . & $7 . .1$ & r r & $7, Y_{1}$ & 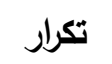 & القوة المميزة بالسرعة للرجلين \\
\hline & $1, \cdot \varepsilon$ & 1.01 & Y५.V० & 1,87 & rV, Tr & درجة & الإرسال \\
\hline & $1,1 r$ & 1.87 & 10.74 & $Y, \diamond \wedge$ & $17, \wedge \vee$ & درجة & الضرب الساحق \\
\hline
\end{tabular}

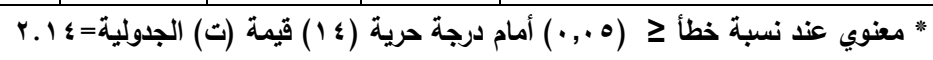

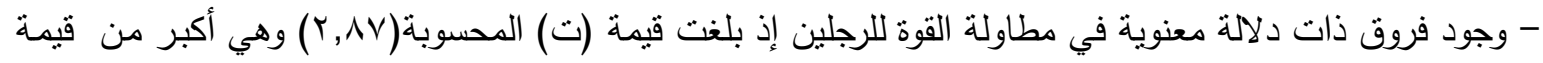

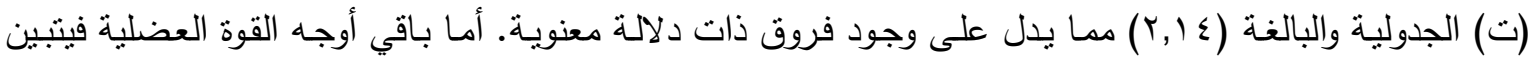

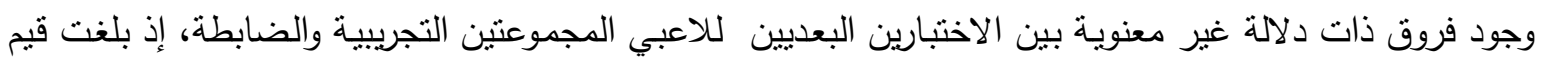

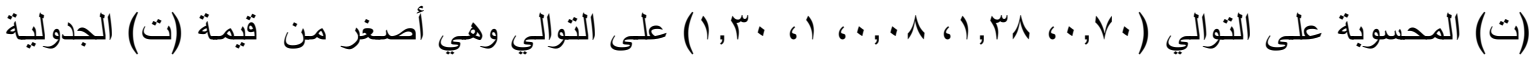

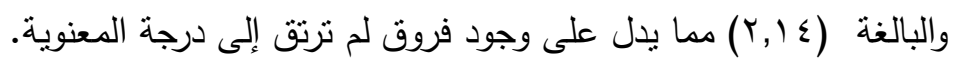

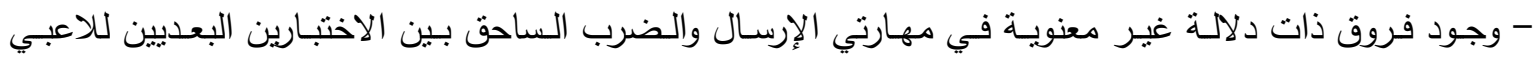

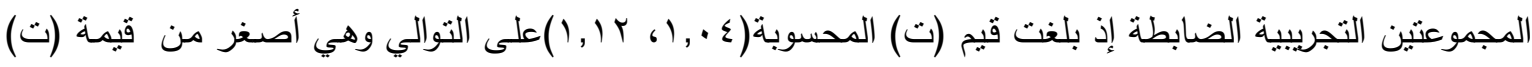



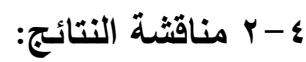
ع - r- امناقثة نتائج الاختبار القبلي والبعدي للمجموعة التجريبية:

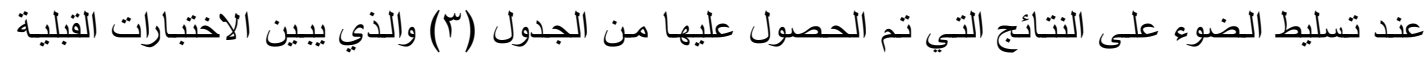

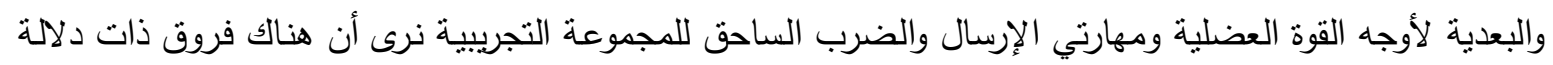

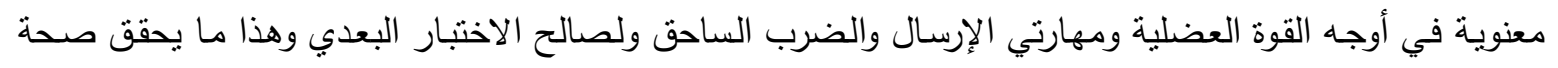

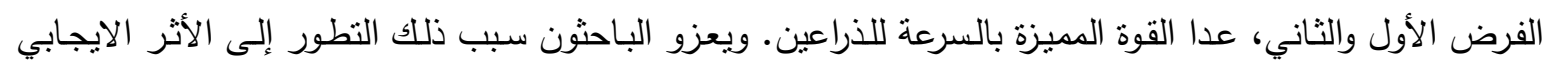

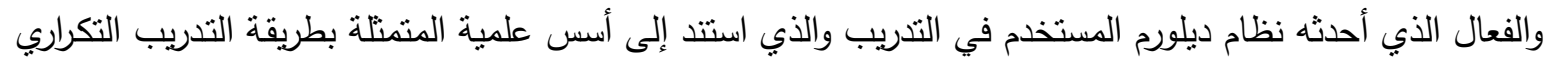

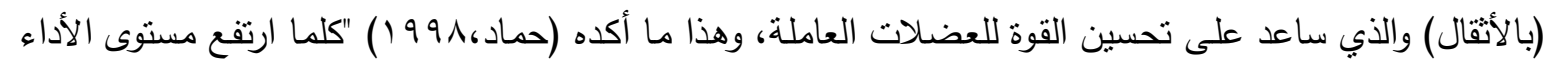

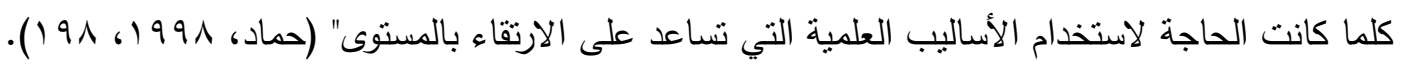




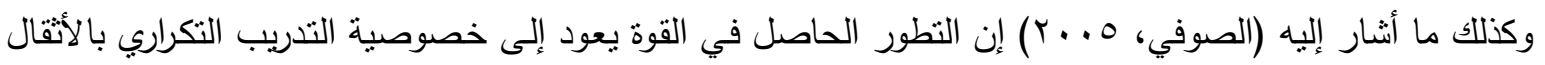

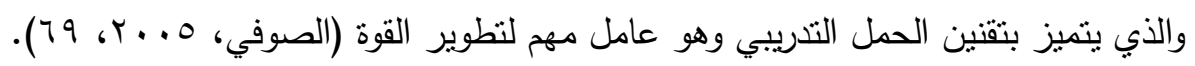

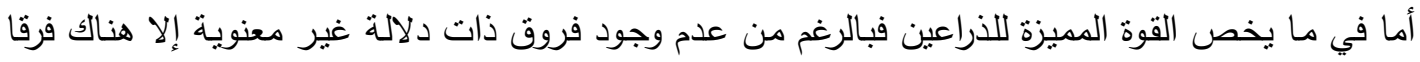
ظاهريا في الأوساط الحسابية ولصالح الاختبار البعدي ويعزو الباحثون سبب ذلك إلك إلى التدريب المستخدم بنظام

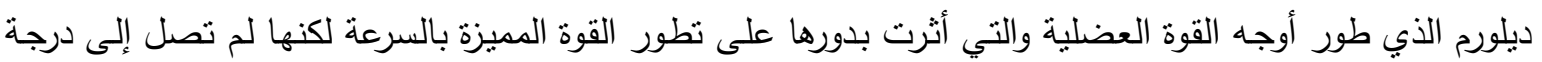

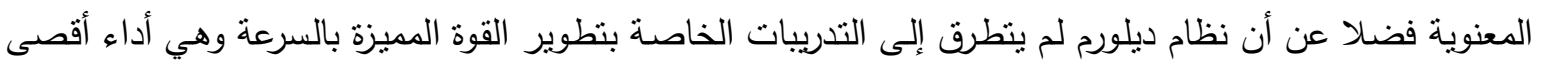

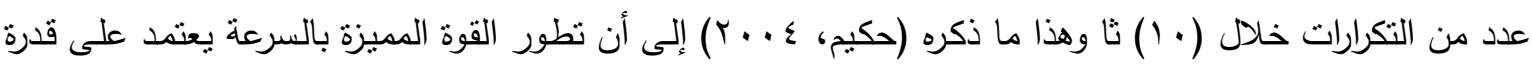

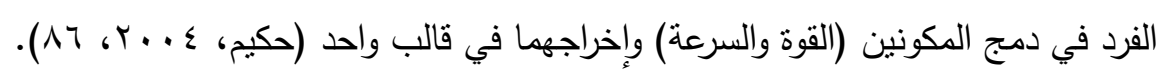

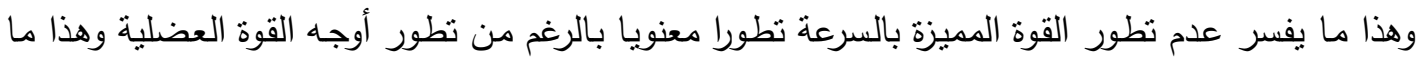

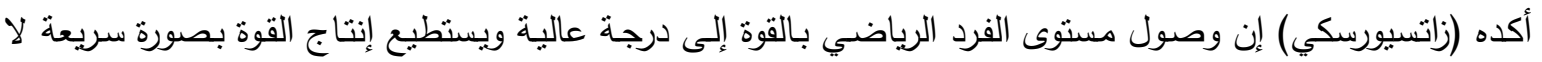

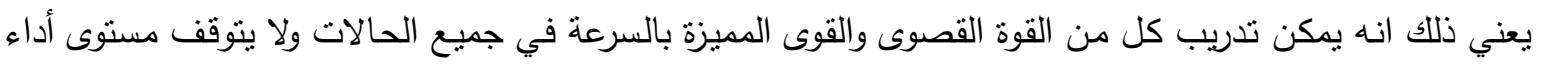

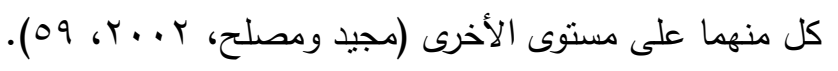

وبالنسبة لمهارتي الإرسال والضرب الساحق فيعزو الباحثون سبب تطور المهارتي إلى اثر المنهاج التدريبي

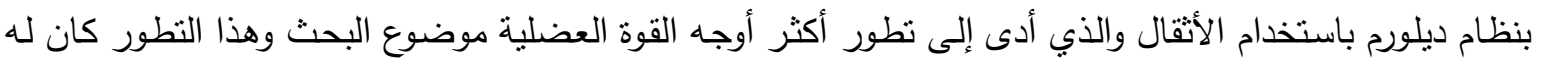

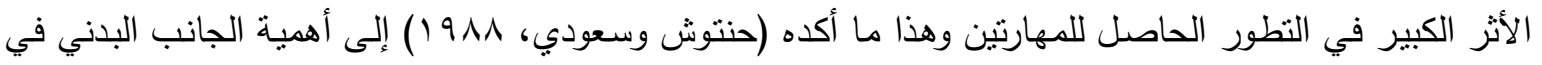

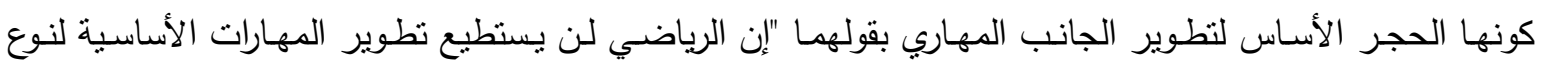

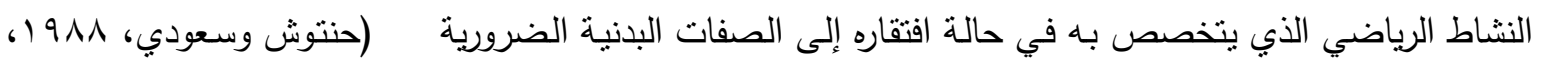

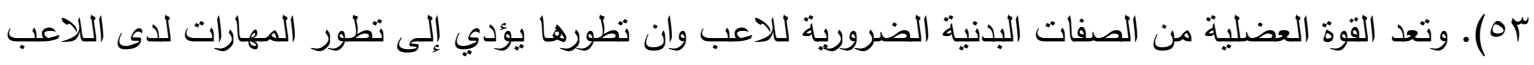

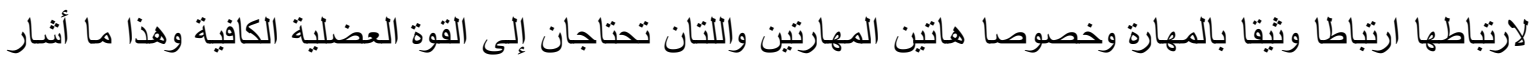

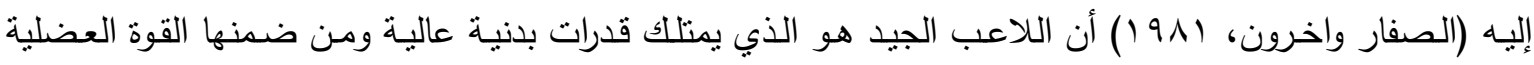

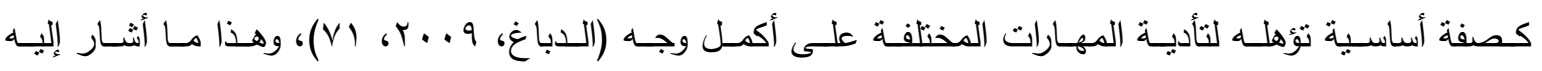
(syd, 1994)

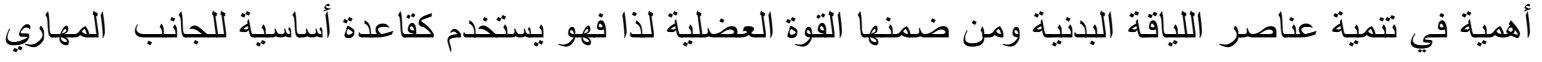

.(syd, 1994, 477)

ع - r - rمناقشة نتائج الاختبار القبلي والبعدي للمجموعة الضابطة:

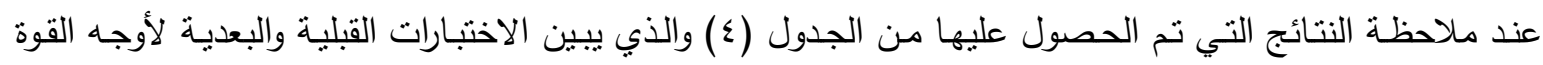

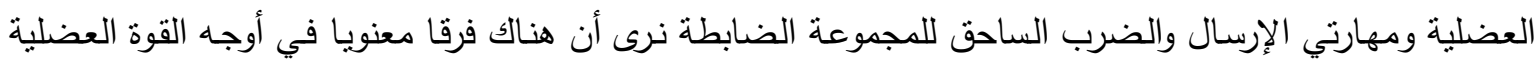

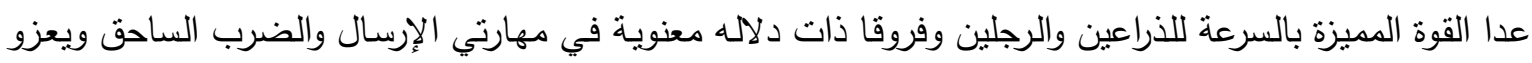

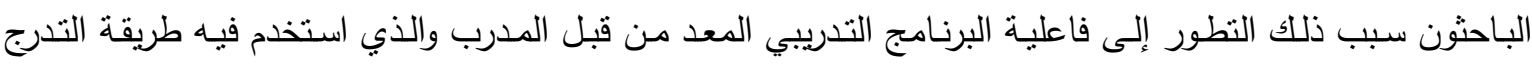

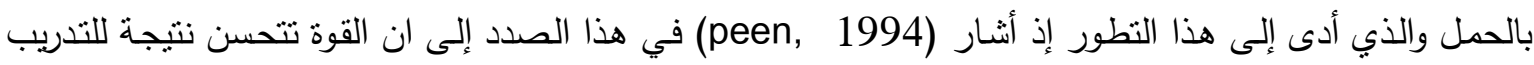

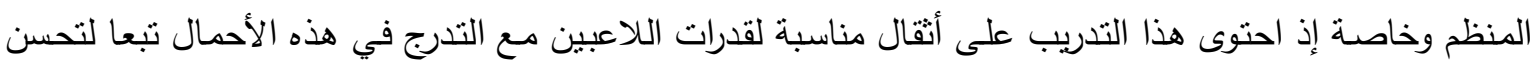

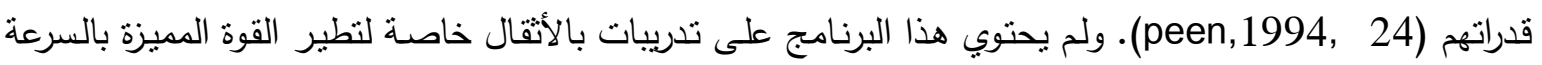
وهذا ما يفسر سبب عدم النطور القوة المميزة بالسرعة للذراعين والرجلين. 


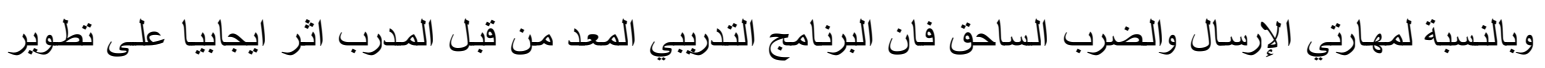

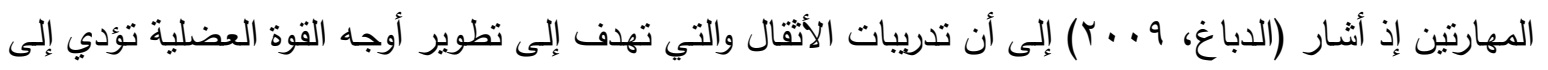

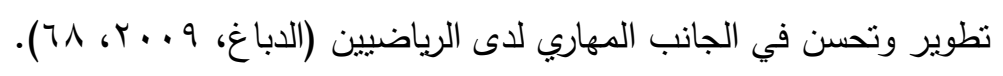
ع - r - م مناقثة نتائج الاختبار (البعدي بعدي) للمجموعتين التجريبية والضابطة:

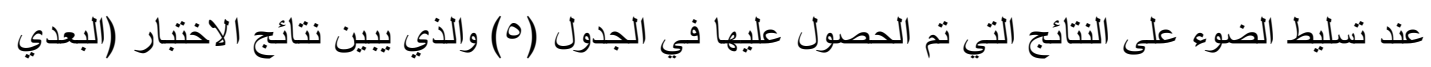

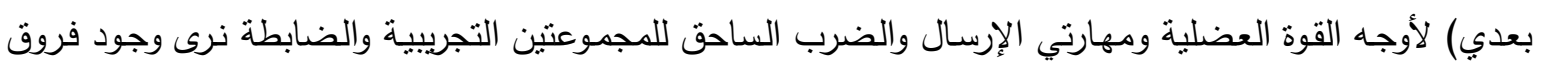

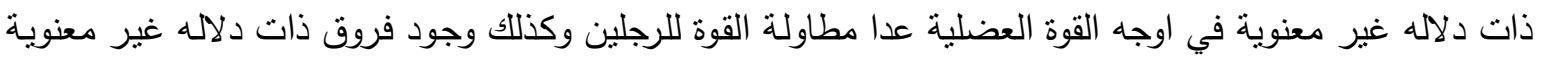

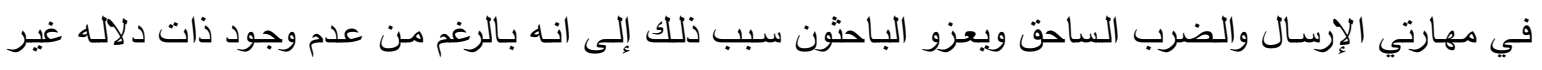

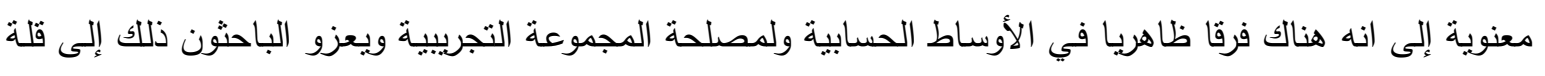

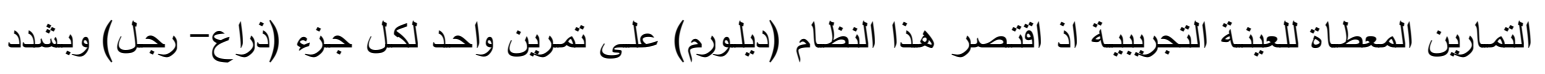

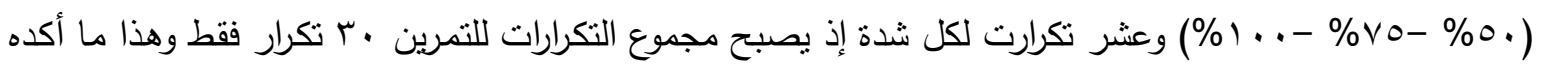
(Grosser, 1989)

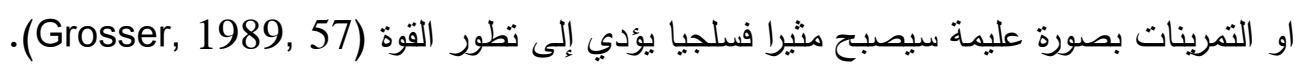



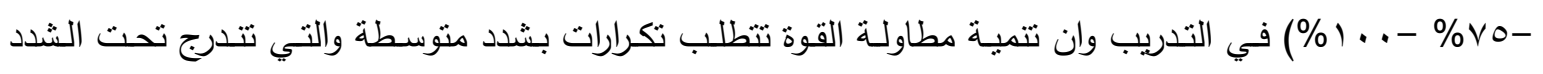



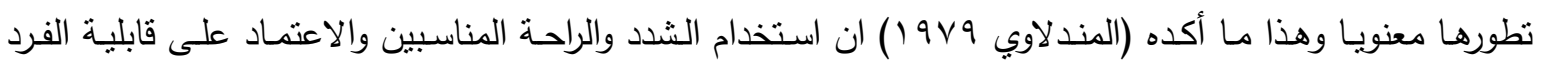

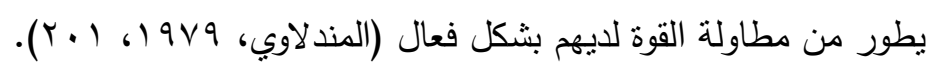

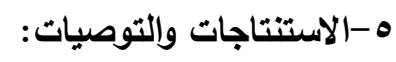

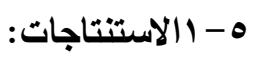

-احدث البرنامج التدريبي للمجموعة التجريبية بنظام ديلورم تطورا معنويا في اغلب أوجه القوة العضلية ومهارتي

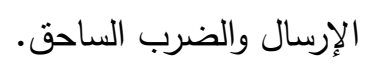
-احدث البرنامج التدريبي للمجموعة التجريبية بنظام ديلورم تطورا في القوة المميزة بالسرعة للذراعين لكن لم يرتق إلى

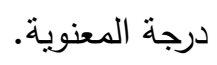
-احدث البرنامج التدريبي للمجموعة الضابطة والمعد من قبل الددرب تطورا معنويا في اغلب أوجه القوة العضلية عدا



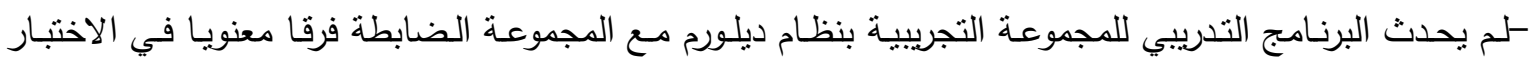

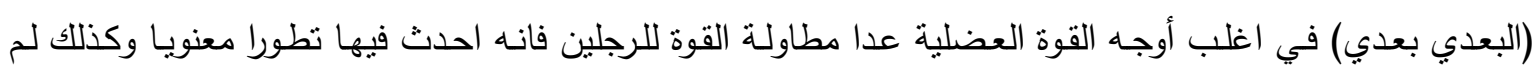

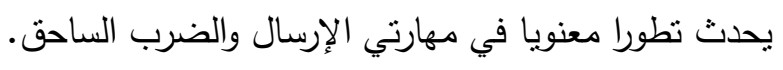

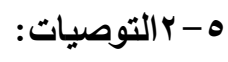


-استخدام نظام ديلورم بزيادة التمارين المستخدمة في الوحدة التدريبية لنحقيق نتائج أفضل. - استخدام نظام ديلورم لفئات عمرية مختلفة ولكلا الجنسين وعلى متغيرات أخرى. 


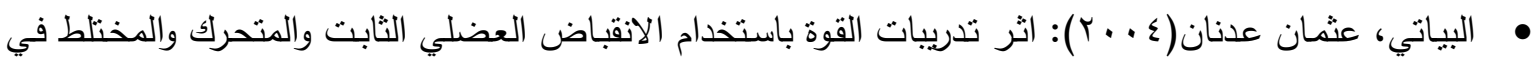
بعض اوجه القوة العضلية والمتغيرات الوظيفية لدى لاعبي كرة اليد الناشئين، رسالة ماجستير ، غير منشورة، كلية التربية الرياضية، جامعة الموصل.

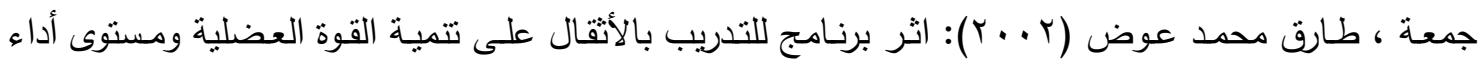

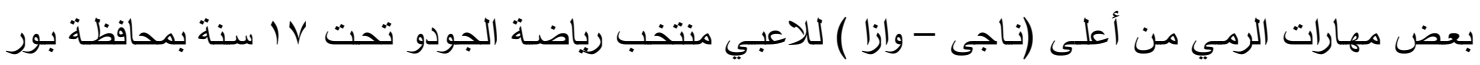

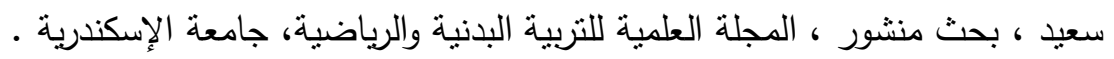

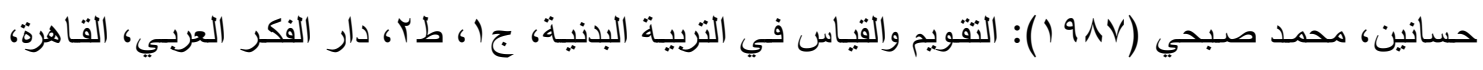
مصر

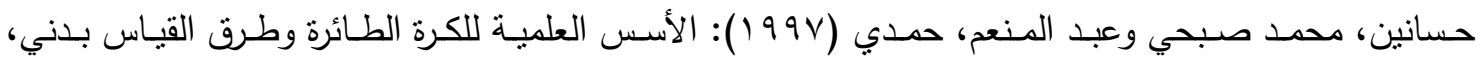

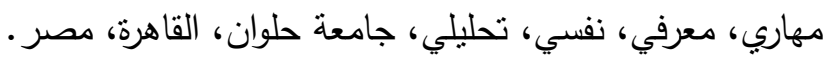
حسين، قاسم حسن (1991 ()): اسس التدريب الرياضي، دار الفكر للطباعة والنشر والتوزيع، عمان، الاردن.


القادسية، العراق. حماد، مفتي ابراهيم (9919 (): التدريب الرياضي الحديث - تخطيط وتطبيق وقيادة، طا، دار الفكر العربي، القاهرة، مصر . حنتوش، معيوف ذنون وسعودي، عامر محمد (911 ()): المدخل في الحركات الأساسية لجمباز الرجال، دار الكتب للطباعة والنشر ، جامعة الموصل، العراق. خطايبة، اكرم زكي (79 99 ( ): موسوعة الكرة الطائرة الحديثة، تاريخ - مهارات - خطط لعب - اعداد بدني اصابات - قياس وتقويم - قواعد اللعبة - الكرة الطائرة المصغرة والثاطئية - مصطلحات رياضية، دار الفكر للطباعة والنشر والتوزيع، عمان، الاردن.

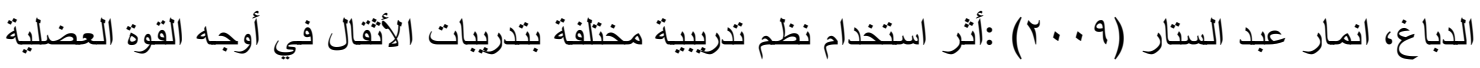
وبعض المهارات الأساسية بالكرة الطائرة، رسالة ماجستير ، غير منشورة، كلية التربية الرياضية،جامعة الموصل.

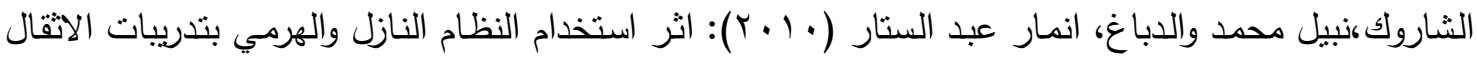

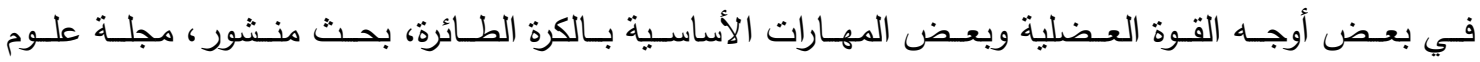

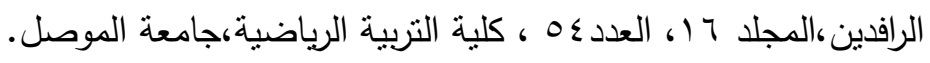
شحاتة، محمد إبراهيم وبريقع، محمد جابر (990 (190): دليل القياسات الجسمية واختبارات الأداء الحركي، منشأة

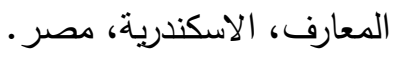

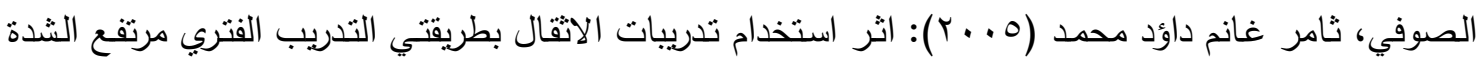

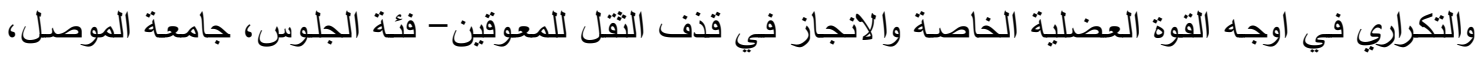
العراق. عبد الجبار، قيس نـاجي و بسطويسي، احمد (9NVV () ): الاختبارات ومبادئ الإحصاء في المجال الرياضس، مطبعة التعليم العالي، بغداد، العراق. عثمان، محمد ( •99 ()): موسوعة العاب القوى: تكنيك، تدريب، تعليم، تحكم، ط (، دار القلم للنشر والتوزيع، 


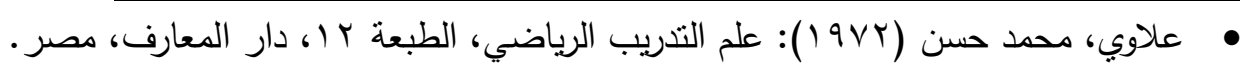

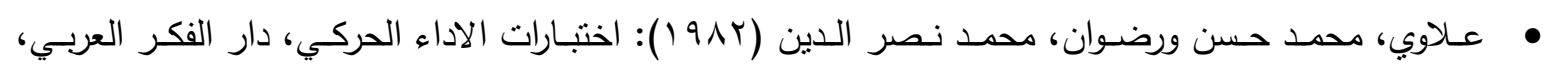

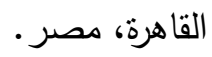

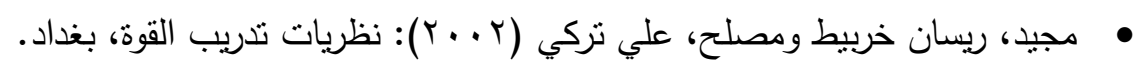

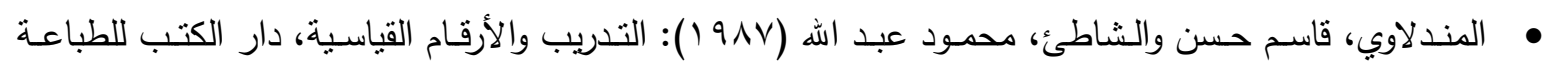
والنشر ، جامعة الموصل، العراق.

• المندلاوي، قاسم واحمد، سعيد احمد (9V9 (1) ): التدريب بين النظرية والنطبيق، بغداد، العراق.

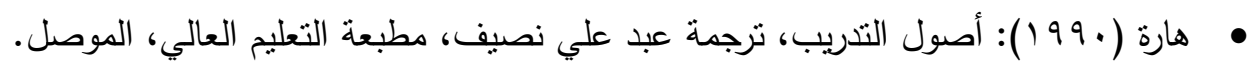

- Bulland, Ernie and knuth, Larry(1977): Triple jump encyclopedia athletic press , 1 st printing USA, .

- Grosser,n,starisch.ka,G(1989): kanditions training, BIV sport wissen munchen.

- Maud, J., Peter \& Foster, Garl (2006): Physiological assessment of Human Fitness, Human Kinetics.

- Peen, X., G.(1994): The Effect of Depth Jump and Weight Training on Vertical Jump Research

- Syd Hoare(1994): The A. Z. of judo publish by Ippon Books, Itd, 4473, Iondon, N12 oAF, England, 


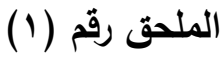

\section{استمارة استبيان}

آراء السادة المختصين والخبراء في مجال علم التدريب الرياضي حول تحديد أوجه القوة العضلية الخاصة بلاعبي

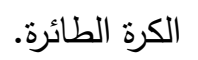

(المحترم

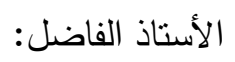
تحية طيبة:

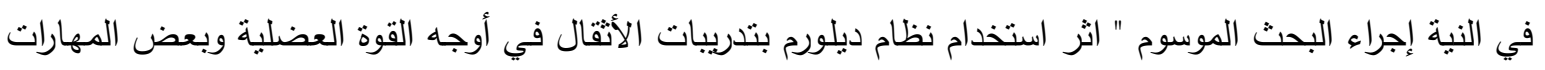



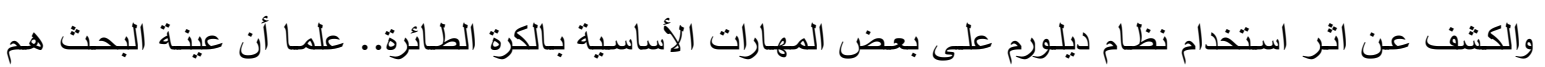
لاعبي نادي نينوى ولفئة الثباب النياب ونظراً لما تتمتعون بها من خبرة ولفئ لعابية في مجال التدريب الرياضي يرجى بيان رأيكم حول أوجه القوة العضلية الخاصة

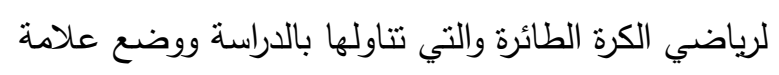
ولكم منا فائق الاحترام والتقدير

$$
\begin{aligned}
& \text { ( ل (أمام العنصر المناسب. } \\
& \text { الاسم الكامل: - الإل } \\
& \text { اللقب العلمي: } \\
& \text { تاريخ الحصول على اللقب العلمي: } \\
& \text { التاريخ: } \\
& \text { التوقيع: - الت }
\end{aligned}
$$

\begin{tabular}{|c|c|c|c|}
\hline & & أوجه القوة العضلية & 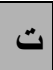 \\
\hline( & ) & القوة القصوى لعضلات الذراعين & 1 \\
\hline( & ) & القوة القصوى لعضلات الرجلين & r \\
\hline( & ) & القوة الانفجارية لعضلات الذراعين & r \\
\hline( & ) & القوة الانفجارية لعضلات الرجلين & $\varepsilon$ \\
\hline( & ) & مطاولة القوة لعضلات الذراعين & 0 \\
\hline( & ) & مطاولة القوة لعضلات الرجلين & 7 \\
\hline( & ) & مطاولة القوة لعضلات البطن & $v$ \\
\hline( & ) & القوة المميزة بالسرعة لعضلات الذراعين & $\wedge$ \\
\hline( & ) & القوة المميزة بالسرعة لعضلات الرجلين & 9 \\
\hline( & ) & القوة المميزة بالسرعة للبطن & 1. \\
\hline
\end{tabular}




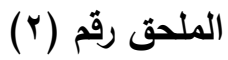

استمارة استبيان

لآراء السادة المختصين والخبراء في مجال القياس والتقويم حول تحديد الاختبار الأنسب لأوجه القوة العضلية


تحية طيية:


المهارات الأساسية بالكرة الطائرة" حيث تهدف هذه الدراسة إلى الكثف عن اثر استخدام نظام ديلورم في أوجه القوة

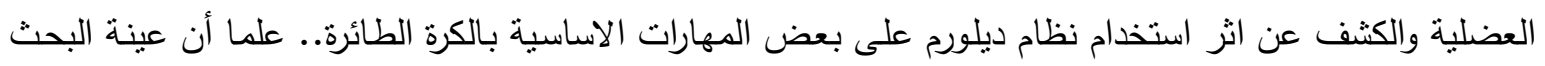

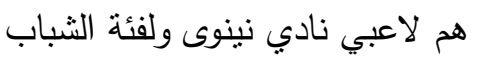
ونظراً لما تتمتعون به من خبرة علمية في القياس والتقويم برجى بيان رأيكم حول تحديد الاختبار الانسب لاوجه القوة

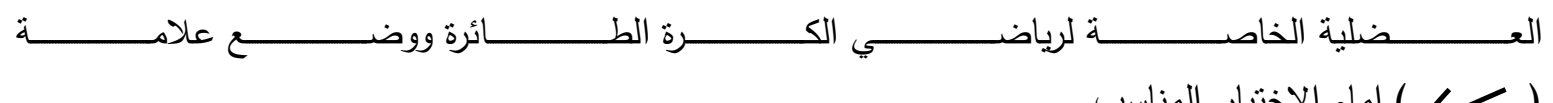
ولكم منا فائق الاحترام والتقدير

$$
\begin{aligned}
& \text { الاسم الكامل: }
\end{aligned}
$$

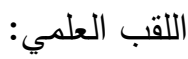

$$
\begin{aligned}
& \text { تاريخ الحصول على اللقب العلمي: } \\
& \text { الكلية والجامعة: } \\
& \text { التاريخ: }
\end{aligned}
$$

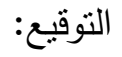




\begin{tabular}{|c|c|c|}
\hline الاشـارة & الاختبارات & اوجه القوة العضلية \\
\hline ) & اختبار القفز العمودي من الثبات & \multirow{3}{*}{ العضلات الرجلين } \\
\hline ) & اختبار الوثب الطويل من الثبات & \\
\hline ) & اختبار (ابالاكوف) & \\
\hline ) & اختبار رمي الكرة الطبية زنة (r) كغم من الوقوف خلف الرأس & \multirow{2}{*}{  } \\
\hline ) & رمي كرة طبية زنة (ץ) كغم من الجلوس على الكرسي & \\
\hline ) & التكرارات حتى استتفاذ الجهد ومد الرجين من مفصل الركبتين من القفز لاقصى عدد من & مطاولــة القوة لعضلات \\
\hline ) & الققز من وضع الجلوس الطويل للاعلى لمدة ( • 9) ثانية & \\
\hline( & اختبار ثني ومد الذراعين من الانبطاح المائل حتى التعب & \multirow{3}{*}{ مطاولـة القـوة لعضلات } \\
\hline( & اختبار التعلق ثني الذراعين (التحمل العضلي الثابت للذراعين) & \\
\hline ) & الغتفين على المتوازي قياس التحمل العضلي الديناميكي للذراعين وحزام & \\
\hline$)$ & اختبار الجلوس من رقود القرفصاء حتى التعب & \multirow{3}{*}{ مطاولـة القوة لعضلات } \\
\hline$)$ & اختبار الجلوس من الروقد من وضع ثني الركبتنين حتى التعب & \\
\hline$)$ & اختبار رفع الرجلين وخفضهما من وضع الاستلقاء & \\
\hline ) & اختبار ضغط البار الحديدي باليدين لاعلى من وضع الوقوف & الذراعين القصوى لعضلات \\
\hline ) & اختبار الجلوس على المقعد والبار الحديدي على الكتقين & \multirow{2}{*}{$\begin{array}{r}\text { الرجلين القصوى لعضلات } \\
\text { الرجلين }\end{array}$} \\
\hline ) & اختبار جلوس القرفصاء الخلفي لرفع اقصى وزن & \\
\hline ) & اختبار ثني الذراعين ومدهما من وضع الانبطاح المائل في (• ث ثانية) & \multirow{2}{*}{ 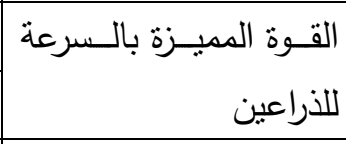 } \\
\hline ) & الانبطاح المائل ثم ثني الذراعين (الاستتاد الامامي) & \\
\hline ) & اختبار ثلات حجلات لاطول مسافة ممكنة ولكل رجل على حدة & 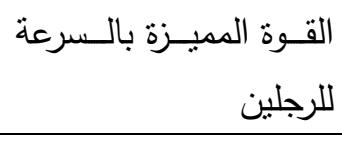 \\
\hline ) & اختبار ثني ومد الركبتين لمدة (• †) ثانية & \\
\hline ) & الحجل لاقصى مسافة خلال (· () ثانية لكل رجل على حدة & \\
\hline$)$ & اختبار الجلوس من الرقود ومن وضع ثني الركبتين خلال ( • ) ثانية & \multirow{2}{*}{ اللبطـوة المميـزة بالــسرعة } \\
\hline$)$ & رفع الجذع من وضع المد ( • () ثانية & \\
\hline
\end{tabular}




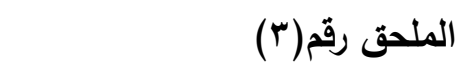 \\ استمارة استبيان}

أثر استفدام نظام ديالمرم بتدريبات الاثقال في اوجه ....

آراء السادة المختصين والخبراء في مجال لعبة الكرة الطائرة حول اختيار بعض المهارات الأساسية

والاختبارات الخاصة بذلك بالكرة الطائرة.

المترم

الأستاذ الفاضل:

تحية طيبة:

في النية إجراء البحث الموسوم " اثر استخدام نظـام ديلـورم بتدريبات الاثقـال في أوجـه القوة العضلية ويعض المهارات الأساسية بالكرة الطائرة" حيث تهدف هذه الدراسة إلى الكثف عن اثر استخدام نظام ديلورم في أوجه القوة العضلية والكثف عن اثر استخدام نظام ديلورم على بعض المهارات الأساسية بالكرة الطائرة.. ونظراً لما تتمتعون بـه من خبرة علمية في مجال لعبة الكرة الطائرة برجى بيان رأيكم حول اختيار بعض المهارات بره بره

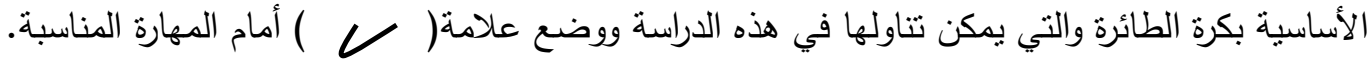
ولكم منا فائق الاحترام والتقدير

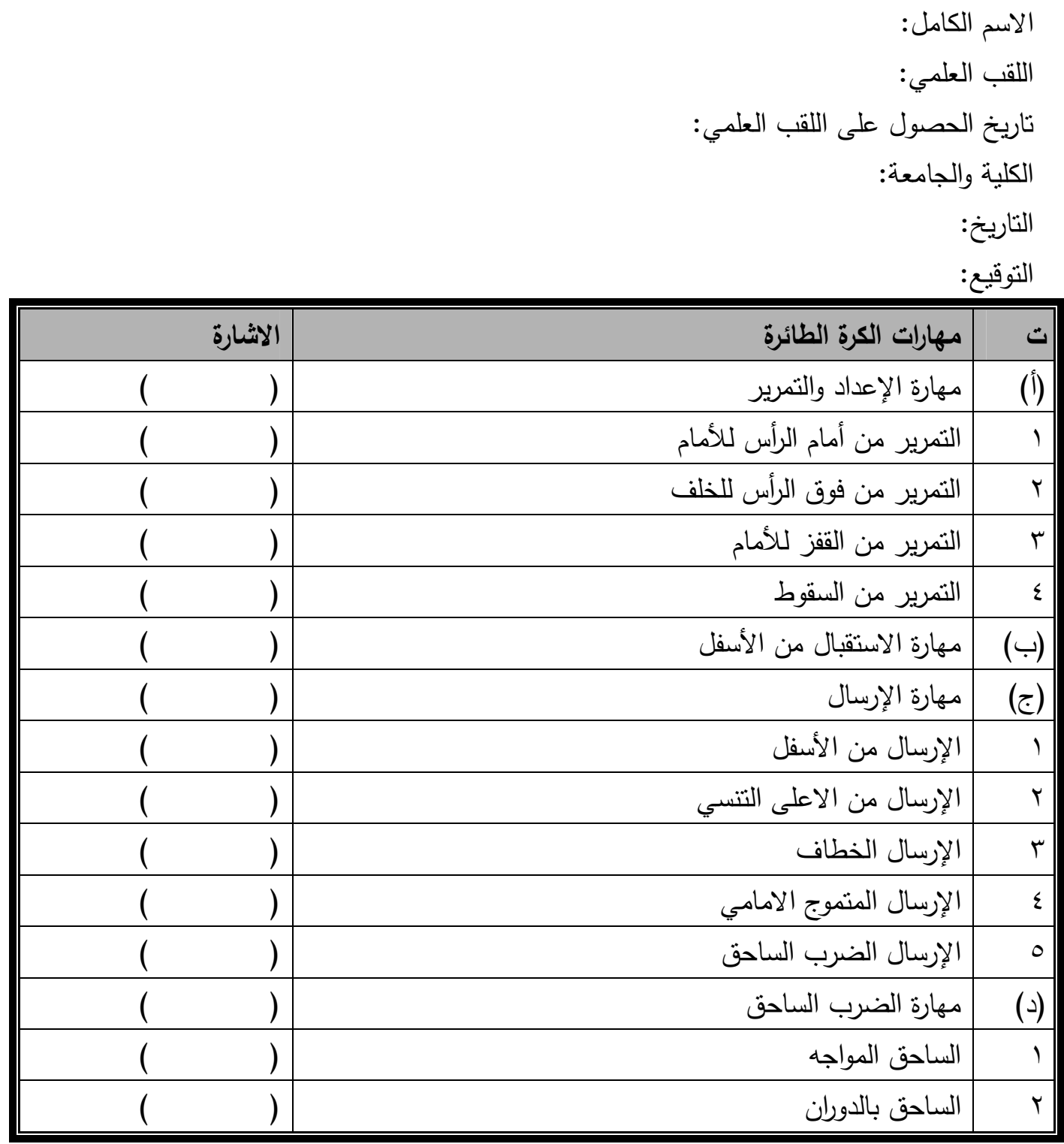

$r \cdot V$ 
أثر استفدام نظام ديالورم بتدريبات الاثقال في اوجه ...

\begin{tabular}{|c|c|c|c|}
\hline( & ) & الساحق بالخداع & $r$ \\
\hline( & ) & الساحق الخطاف & $\varepsilon$ \\
\hline ( & ) & الساحق من المنطق الخلفية & 0 \\
\hline( & ) & حائط الصد & $(ه)$ \\
\hline( & ) & حائط الصد الفردي & 1 \\
\hline( & ) & حائط الصد الزوجي & $r$ \\
\hline ( & ) & حائط الصد الثلاثي & $r$ \\
\hline
\end{tabular}




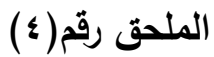

استمارة استبيان

آراء السادة الخبراء والمتخصصين في مجال القياس والتقويم ولعبة كرة الطائرة حول تحديد الاختبار الأنسب للمهارات الأساسية بكرة الطائرة. المحترم الأستاذ الفاضل:

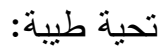

في النية اجراء البحث الموسوم " اثر استخدام نظـام ديلـورم بتدريبات الاثقـال في أوجـه القوة العضلية ويعض المهارات الأساسية بالكرة الطائرة" حيث تهدف هذه الدراسة إلى الكثف عن اثر استخدام نظام ديلورم في اوجه القوة

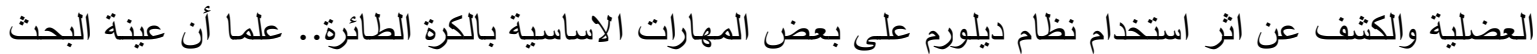
هم لاعبي نادي نينوى ولفئة الثباب ونظراً لما تتمتعون بـه من خبرة علمية في القياس والتقويم ولعبة كرة الطائرة يرجى بيان رأيكم حول تحديد الاختبار

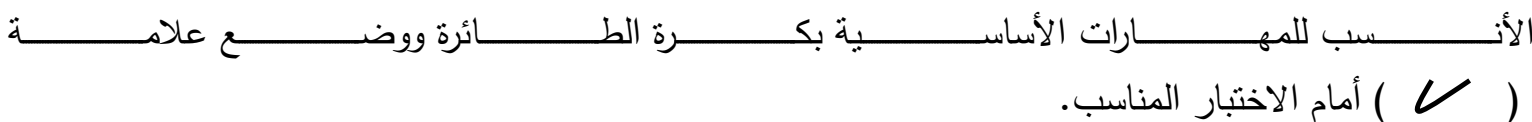
ولكم منا فائق الاحترام والتقدير

$$
\begin{aligned}
& \text { الاسم الكامل: } \\
& \text { اللقب العلمي: } \\
& \text { تاريخ الحصول على اللقب العلمي: } \\
& \text { الكلية والجامعة: } \\
& \text { التاريخ: }
\end{aligned}
$$

\begin{tabular}{|c|c|c|}
\hline 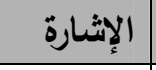 & 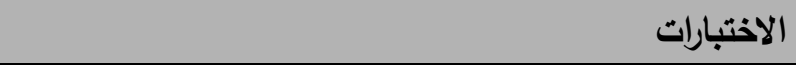 & المهارات الأساسية \\
\hline( & اختبار دقة الإرسال التتسي & \multirow[t]{2}{*}{ الإرسال من الأعلى التتسي } \\
\hline ) & اختبار الإرسال من أعلى آو من أسفل (قياس دقة الإرسال) & \\
\hline ) & اختبار دقة الضرب الساحق & الضرب الساحق المواجه \\
\hline
\end{tabular}

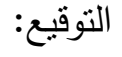

ملاحظة: السيد الخبير المحترم يمكن إضافة أي اختبار تراه مناسبا لأي مهارة 


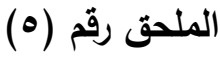

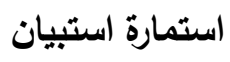

آراء السادة المختصبن والخبراء في مجال علم التذريب الرياضي حول صلاحية البرنامج التنريبي.

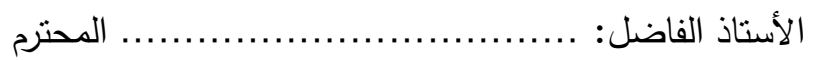
تحية طيية:

في النية اجراء البحث الموسوم " اثر استخدام نظام ديلورم بتدريبات الاثقال في أوجـه القوة العضلية

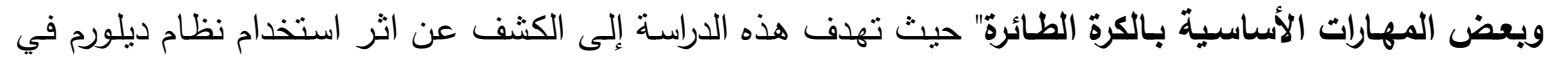

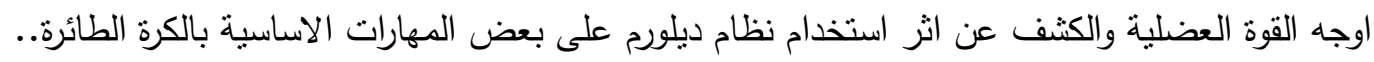

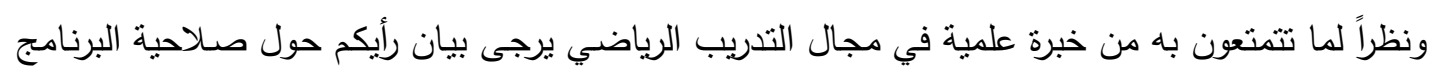

$$
\begin{aligned}
& \text { ولكم منا فائق الاحترام والتقدير } \\
& \text { التدريبي. }
\end{aligned}
$$

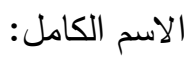

$$
\begin{aligned}
& \text { اللقب العلمي: } \\
& \text { تاريخ الحصول على اللقب العلمي: }
\end{aligned}
$$



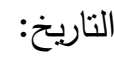

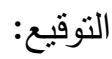

$$
\begin{aligned}
& \text { الباحثون } \\
& \text { النقاط الواجب مراعاتها عند تنفيذ المنهاج التدريبي: } \\
& \text { V تطبيق المنهاج كجزء من الوحدات التريبية المتكاملة اي جزء من القسم الرئيسي. }
\end{aligned}
$$

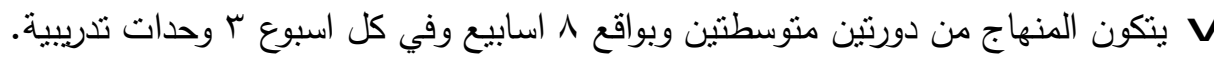

$$
\begin{aligned}
& \text { V يكون تموج حركة الحمل (ب : ( ).) } \\
& \text { بعد كل اربعة اسابيع يتم تحديد القيم القصوى لكل لاعب والعمل بموجب ذللك. }
\end{aligned}
$$

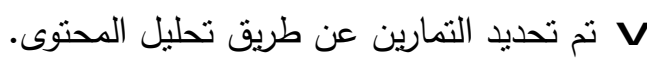

$$
\begin{aligned}
& \text { ت تحديد الثدة والتكرارات وفترات الراحة عن طريق تحليل الدحتوى والتجربة الاستطلاعية. }
\end{aligned}
$$

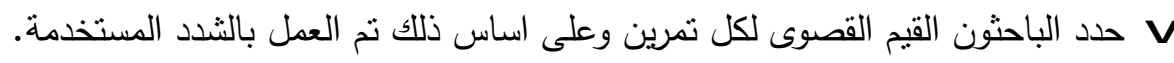




\begin{tabular}{|c|c|c|c|c|c|c|}
\hline & & & & & \multicolumn{2}{|c|}{ البرنامج التدريبي: } \\
\hline التراريـة بـين & الرجامــة بــين & التكرار & الثدة & اسم التمرين & المجموعة & اليوم \\
\hline$د \varepsilon-r$ & $د-r$ & $\begin{array}{l}1 . \\
1 . \\
1 .\end{array}$ & $\begin{array}{l}\% \circ . \\
\% \vee 0 \\
\% 1 \ldots\end{array}$ & الضغط الامامي & (نظام ديلورم) & السبت \\
\hline$د \leqslant-r$ & $د-r$ & $\begin{array}{l}1 . \\
1 . \\
1 .\end{array}$ & $\begin{array}{l}\% \circ \\
\% \vee 0 \\
\% 1 \ldots\end{array}$ & جلــــوس نـــــف & & \\
\hline r & r & $\begin{array}{l}1 . \\
1 . \\
1 .\end{array}$ & $\begin{array}{l}\% \circ . \\
\% \vee 0 \\
\% 1 \ldots\end{array}$ & كيرل سواعد امامي & (نظام ديلورم) & الاثثين \\
\hline$د \leqslant-r$ & $د-r$ & $\begin{array}{l}1 . \\
1 . \\
1 .\end{array}$ & $\begin{array}{l}\% \circ . \\
\% \vee 0 \\
\% 1 \ldots\end{array}$ & كيرل سيقان امامي & & \\
\hline r - - د & L & $\begin{array}{l}1 . \\
1 . \\
1 .\end{array}$ & $\begin{array}{l}\% \circ . \\
\% \vee 0 \\
\% 1 \ldots\end{array}$ & ترايسبس & (نظام ديلورم) & الاربعاء \\
\hline r & $د-r$ & $\begin{array}{l}1 . \\
1 .\end{array}$ & $\begin{array}{l}\% \circ . \\
\% \vee 0 \\
\% 1 \ldots\end{array}$ & كيرل سيقان خلفي & & \\
\hline الراحة & الراحة & التكرار & الثدة & اسم التمرين & المجموعة & 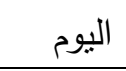 \\
\hline د & $M-r$ & $\begin{array}{l}1 \\
V \\
0 \\
\varepsilon \\
r \\
r \\
1\end{array}$ & $\begin{array}{c}\% \vee \\
\% \vee ० \\
\% \wedge . \\
\% \wedge ० \\
\% 9 . \\
\% 90 \\
\% 1 . .\end{array}$ & الضغط الامامي & (منهاج الثنية & السبت \\
\hline r & & $\begin{array}{l}\Lambda \\
v \\
0 \\
\varepsilon \\
r\end{array}$ & $\begin{array}{l}\% \vee . \\
\% \vee ० \\
\% \wedge . \\
\% \wedge ० \\
\% ৭ .\end{array}$ & جلــــوس نـــــف & & \\
\hline
\end{tabular}




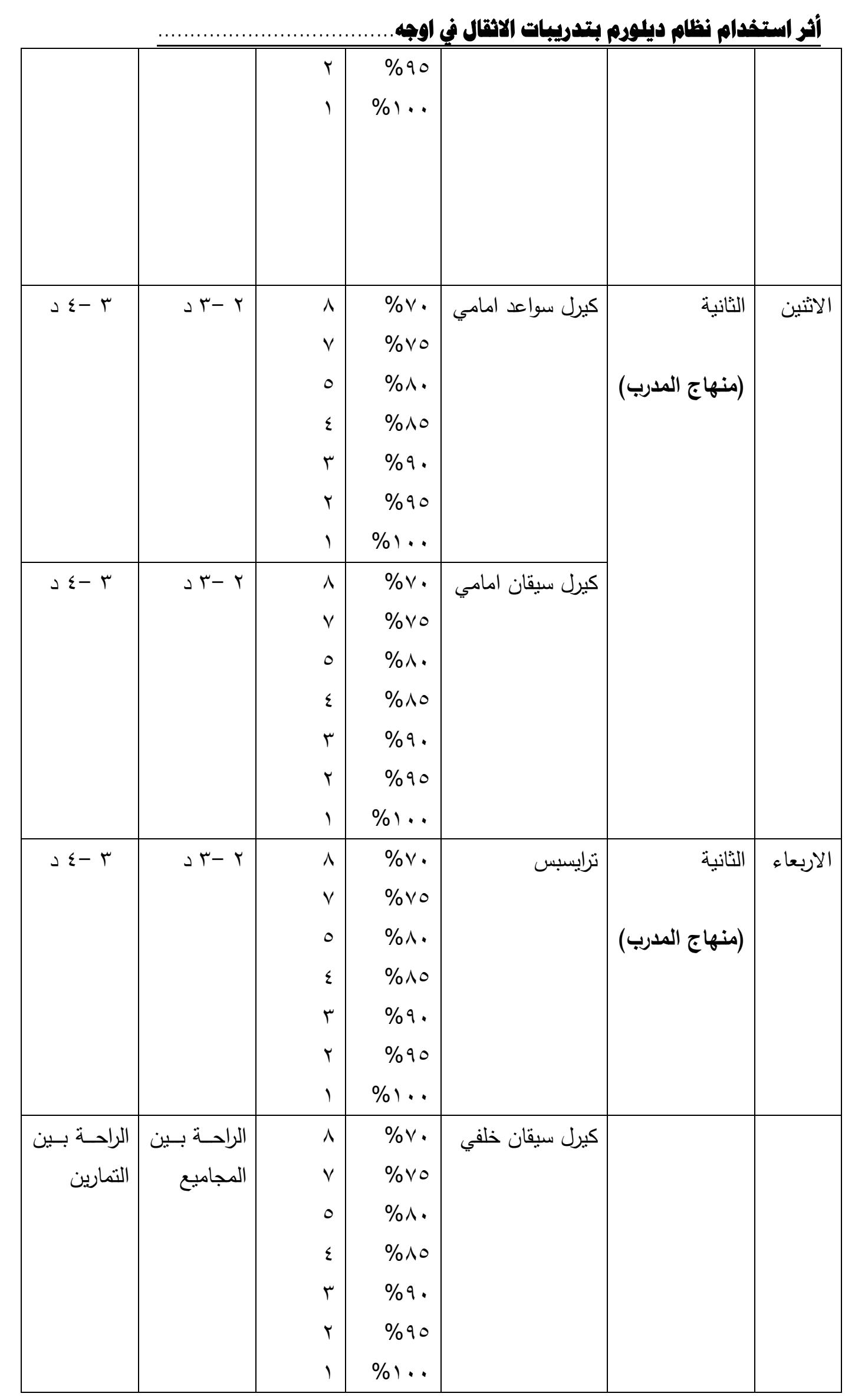

\section{rir}

